\title{
Interpretation of organic components from Positive Matrix Factorization of aerosol mass spectrometric data
}

\author{
I. M. Ulbrich ${ }^{1,2}$, M. R. Canagaratna ${ }^{3}$, Q. Zhang ${ }^{4}$, D. R. Worsnop ${ }^{3}$, and J. L. Jimenez ${ }^{1,2}$ \\ ${ }^{1}$ Cooperative Institute for Research in the Environmental Sciences (CIRES), Boulder, CO, USA \\ ${ }^{2}$ Department of Chemistry and Biochemistry, University of Colorado, Boulder, CO, USA \\ ${ }^{3}$ Aerodyne Research, Inc., Billerica, MA, USA \\ ${ }^{4}$ Atmos. Sci. Res. Center, University at Albany, State University of New York, Albany, NY, USA
}

Received: 27 February 2008 - Published in Atmos. Chem. Phys. Discuss.: 9 April 2008

Revised: 2 April 2009 - Accepted: 14 April 2009 - Published: 5 May 2009

\begin{abstract}
The organic aerosol (OA) dataset from an Aerodyne Aerosol Mass Spectrometer (Q-AMS) collected at the Pittsburgh Air Quality Study (PAQS) in September 2002 was analyzed with Positive Matrix Factorization (PMF). Three components - hydrocarbon-like organic aerosol OA (HOA), a highly-oxygenated OA (OOA-1) that correlates well with sulfate, and a less-oxygenated, semi-volatile OA (OOA-2) that correlates well with nitrate and chloride - are identified and interpreted as primary combustion emissions, aged SOA, and semivolatile, less aged SOA, respectively. The complexity of interpreting the PMF solutions of unit mass resolution (UMR) AMS data is illustrated by a detailed analysis of the solutions as a function of number of components and rotational forcing. A public web-based database of AMS spectra has been created to aid this type of analysis. Realistic synthetic data is also used to characterize the behavior of PMF for choosing the best number of factors, and evaluating the rotations of non-unique solutions. The ambient and synthetic data indicate that the variation of the PMF quality of fit parameter ( $Q$, a normalized chi-squared metric) vs. number of factors in the solution is useful to identify the minimum number of factors, but more detailed analysis and interpretation are needed to choose the best number of factors. The maximum value of the rotational matrix is not useful for determining the best number of factors. In synthetic datasets, factors are "split" into two or more components when solving for more factors than were used in the input. Elements of the "splitting" behavior are observed in solutions of real datasets with several factors. Significant structure remains in the residual of the real dataset after physically-meaningful factors have been assigned and an unrealistic number of fac-
\end{abstract}

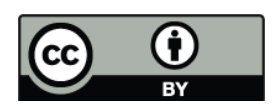

Correspondence to: J. L Jimenez

(jose.jimenez@colorado.edu) tors would be required to explain the remaining variance. This residual structure appears to be due to variability in the spectra of the components (especially OOA-2 in this case), which is likely to be a key limit of the retrievability of components from AMS datasets using PMF and similar methods that need to assume constant component mass spectra. Methods for characterizing and dealing with this variability are needed. Interpretation of PMF factors must be done carefully. Synthetic data indicate that PMF internal diagnostics and similarity to available source component spectra together are not sufficient for identifying factors. It is critical to use correlations between factor and external measurement time series and other criteria to support factor interpretations. True components with $<5 \%$ of the mass are unlikely to be retrieved accurately. Results from this study may be useful for interpreting the PMF analysis of data from other aerosol mass spectrometers. Researchers are urged to analyze future datasets carefully, including synthetic analyses, and to evaluate whether the conclusions made here apply to their datasets.

\section{Introduction}

Fine particles have important effects on human health, visibility, climate forcing, and deposition of acids and nutrients to ecosystems and crops. Organic species represent an important fraction of the submicron aerosol at most locations (Kanakidou et al., 2005; Zhang et al., 2007a). Typically referred to as organic aerosols (OA), they are the sum of multiple primary and secondary sources that can evolve due to aging processes. Apportioning organic aerosols into their sources and components correctly is a critical step towards enabling efficient control strategies and model representations. 
The organic source apportionment problem has been approached by several techniques. Turpin and Huntzicker (1991) utilized the ratio between elemental carbon and organic carbon (EC/OC) from filter samples to estimate primary and secondary OA. Schauer et al. (1996) used molecular markers with a chemical mass balance (CMB) approach to apportion OA extracted from filters and analyzed by GCMS. Several sources with unique markers can be identified, but source profiles must be known a priori, sources without unique markers are not easily separated, and only primary OA sources are identified. Szidat et al. (2006) have separated anthropogenic and biogenic OA based on water solubility and ${ }^{14} \mathrm{C} /{ }^{12} \mathrm{C}$ ratios and found a major biogenic influence in Zurich, Switzerland. The technique has very low time resolution (many hours to several days) and can identify only a few categories of sources. Traditional OA filter measurements suffer from low time resolution (several hrs. to days) and positive and negative artifacts (Turpin et al., 2000).

The last 15 years have seen the development of a new generation of real-time aerosol chemical instrumentation, most commonly based on mass spectrometry or ion chromatography (Sullivan et al., 2004; DeCarlo et al., 2006; Williams et al., 2006; Canagaratna et al., 2007; Murphy, 2007). Current real-time instruments can produce data over timescales of seconds to minutes and have reduced sampling artifacts compared to filters. Single-particle mass spectrometers (e.g., PALMS, ATOFMS, SPLAT) have used particle classification systems to group particles based on composition or other characteristics (Murphy et al., 2003). A fast GC-MS system (TAG) has been developed that may allow the application of the molecular marker technique with much faster time resolution than previously possible (Williams et al., 2006). However GC-MS as typically applied discriminates against oxygenated organic aerosols (OOA) (Huffman et al., 2009), which is the dominant ambient OA component (Zhang et al., 2007a), and thus may limit the applicability of this technique by itself. It is highly desirable to perform source apportionment based on the composition of the whole OA. This information cannot be obtained at the molecular level with current techniques, however several techniques are starting to characterize the types/groups of species in bulk OA (Fuzzi et al., 2001; Russell, 2003; Zhang et al., 2005a, c).

The Aerodyne Aerosol Mass Spectrometer (AMS) belongs to the category of instruments that seeks to measure and characterize the whole OA. It has been designed to quantitatively measure the non-refractory components of submicron aerosol with high time resolution (Jayne et al., 2000; Jimenez et al., 2003) and produces ensemble average spectra for organic species every few seconds to minutes (Allan et al., 2004). Several groups have attempted different methods to deconvolve the OA spectral matrix measured by a Q-AMS (Zhang et al., 2005a, c, 2007a; Marcolli et al., 2006; Lanz et al., 2007). Zhang et al. (2005a) first showed that information on OA sources could be extracted from linear decomposition of AMS spectra by using a custom principal component anal- ysis (CPCA) method applied to OA data from the Pittsburgh Supersite from 2002. The resulting factors were identified as hydrocarbon-like organic aerosol (HOA, a reduced OA) and oxygenated organic aerosol (OOA) and were strongly linked to primary and secondary organic aerosol (POA and SOA), respectively, based on comparison of their spectra to known sources and their time series to other tracers. OOA was found to dominate OA ( $\sim 2 / 3$ of the OA mass was OOA), in contrast to previous results at this location (Cabada et al., 2004). Zhang et al. (2007a) used the Multiple Component Analysis technique (MCA, an expanded version of the CPCA) for separating more than two factors in datasets from 37 field campaigns in the Northern Hemisphere and found that the sum of several OOAs comprises more of the organic aerosol mass than HOA at most locations and times, and that in rural areas the fraction of HOA is usually very small. Marcolli et al. (2006) applied a hierarchical cluster analysis to Q-AMS data from the New England Air Quality Study (NEAQS) from 2002. Clusters in this data represented biogenic VOC oxidation products, highly oxidized OA, and other small categories. Lanz et al. (2007) applied Positive Matrix Factorization (PMF) (Paatero and Tapper, 1994; Paatero, 1997) to the organic fraction of a Q-AMS dataset from Zurich in the summer of 2005. The six factors identified in this study were HOA, two types of OOA (a highly-oxidized, thermodynamically stable type called OOA-1 that correlates well with aerosol sulfate; and a less-oxidized, semi-volatile type called OOA-2 that correlates well with aerosol nitrate), charbroiling, wood burning, and a minor source that may be influenced by food cooking. Lanz et al. (2008) applied a hybrid receptor model (combining CMB-style a priori information of factor profiles with the bilinear PMF model) specified by the Mulilinear Engine (ME-2, Paatero, 1999) to apportion the organic fraction of a Q-AMS dataset from Zurich during wintertime inversions, when no physically-meaningful components could be identified by the bilinear model alone. Three factors, representing HOA, OOA, and wood burning aerosol, were identified, with OOA and wood-burning aerosol accounting for $55 \%$ and $38 \%$ of the mass, respectively. More advanced source apportionment methods based on Bayesian statistics, which output a probability distribution instead of scalars for each element of the source profiles and time series and thus contain information necessary for a statistical evaluation of the uncertainty of the output, are under development (Christensen et al., 2007; Lingwall et al., 2008). Bayesian models can also incorporate prior information in a natural and probabilistically rigorous way by specification of the "prior distribution" for each variable. Bayesian methods are expensive computationally, and the more complex output requires greater review by the researcher. Bayesian methods have not been applied to aerosol MS data to our knowledge.

Of the analysis techniques mentioned above, PMF is the most widely used in the atmospheric research community (Lee et al., 1999; Ramadan et al., 2000; Kim et al., 2003; Xie et al., 1999; Larsen and Baker, 2003; Maykut et al., 
2003) and its application to PM has been recently summarized in two separate reviews (Reff et al., 2007; Engel-Cox and Weber, 2007). PMF is a receptor-only, factorization model based on mass conservation which requires no a priori information about factor profiles or time trends. PMF has generally been applied to long-term, low-time-resolution datasets, though there has been a call for greater application of source apportionment techniques to air pollution events to facilitate understanding of specific sources for regulatory purposes (Engel-Cox and Weber, 2007). As shown schematically in Fig. 1, PMF is a bilinear unmixing model in which a dataset matrix is assumed to be comprised of the linear combination of factors with constant profiles that have varying contributions across the dataset. All of the values in the profiles and contributions are constrained to be positive. The model can have an arbitrary number of factors; the user must select the solution that "best" explains the data. This is often the most subjective and least quantitative step of PMF analysis and relies greatly on the judgment and skill of the modeler (Engel-Cox and Weber, 2007; Reff et al., 2007). In addition, mathematical deconvolution of a dataset often yields non-unique solutions, in which linear transformations (colloquially referred to as "rotations") of the factors are possible while the positivity constraint is maintained. The necessity of choosing a number of factors and a particular rotation often complicates the interpretation of the solutions. As clearly articulated by P. Paatero, personal communication, 2007:

"It is unfortunate that introducing a priori information also introduces some subjectivity in the analysis [...] However, the tradeoff is often between a successful albeit subjectively aided analysis and an unsuccessful analysis. [...] subjective decisions must be fully and openly reported in publications. [...] Hiding the details of subjective decisions or even worse, pretending that no subjectivity is included in the analysis, should not be tolerated in scientific publications".

Although the application of PMF analysis to data from the AMS and other aerosol mass spectrometers is relatively new, it is quickly becoming widespread. Thus, a detailed characterization of the capabilities and pitfalls of this type of analysis when applied to aerosol MS data is important. UMR AMS datasets are very large with typically several million datapoints $(\sim 300 \mathrm{~m} / \mathrm{z}$ 's per sample, with $\sim 8000$ samples for a month-long campaign with 5 min averaging) and fragmentation of molecules during ionization gives each mass spectrum strongly interrelated data. AMS datasets differ in two fundamental ways from most atmospheric datasets to which PMF has been applied. The structure, internal correlation between some $\mathrm{m} / \mathrm{z}$ 's created by significant fragmentation of molecules in the vaporization and ionization processes in the AMS, and precision of AMS data are significantly different from datasets of multiple aerosol components (metals, organic and elemental carbon, ions, etc.) measured by several instruments typically used with PMF in previous studies. The error structure is also more coherent and self-consistent due to the use of data from a single instrument, rather than

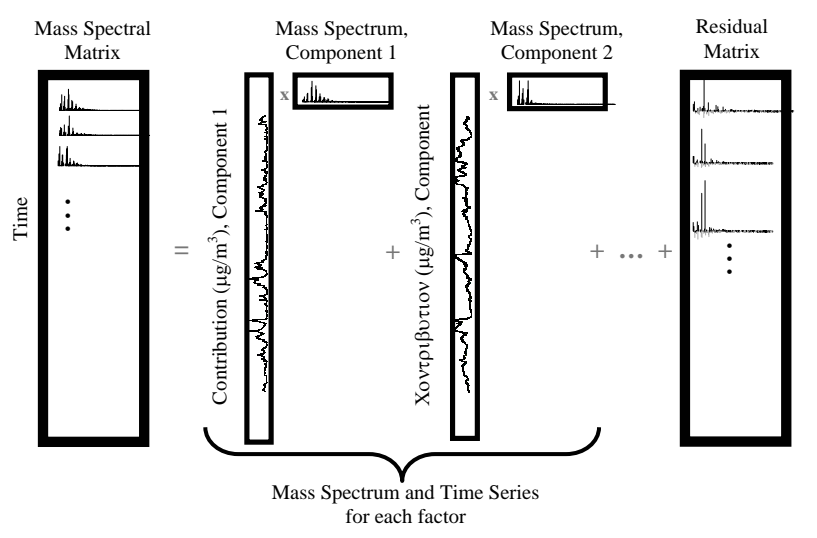

Fig. 1. Schematic of PMF factorization of an AMS dataset. The time series of the factors make up the matrix $\mathbf{G}$ and the mass spectra of the factors make up the matrix $\mathbf{F}$ in Eq. (1).

mixing data from different instruments for which the relative errors may be more difficult to quantify precisely, or that may drift differently, etc.

In this work, we apply PMF to data obtained with the quadrupole Aerosol Mass Spectrometer (Q-AMS) during the Pittsburgh Air Quality Study. Three factors, interpreted as HOA, aged regional OOA, and fresh, semivolatile OOA are reported for the Pittsburgh ambient dataset. The ambiguities associated with choosing the number of factors and their best rotations are reported. In addition, sensitivity analyses are performed with synthetic datasets constructed to retain the inherent structure of AMS data and errors. We explore methods that can inform the choice of the appropriate number of factors and rotation for AMS OA datasets, as well as investigate the retrievability of small factors.

\section{Methods}

\subsection{Aerosol Mass Spectrometer (AMS)}

The Q-AMS has been described in detail elsewhere (Jayne et al., 2000; Jimenez et al., 2003) and only a brief summary is given here. The AMS consists of three main parts: an inlet system which generates a particle beam, a particle sizing section, and a particle composition analysis section. The inlet focuses submicron particles into a narrow beam. A mechanical chopper allows all particles ("beam open"), no particles ("beam closed"), or a packet of particles ("beam chopped") to pass to the particle sizing region. Particles impact on a flash vaporizer $\left(600^{\circ} \mathrm{C}\right)$ at the rear of the sizing region under high vacuum $\left(\sim 10^{-7}\right.$ Torr $)$. The vapors from non-refractory components are ionized by electron impact $(70 \mathrm{eV})$ and the resultant positively charged ions are analyzed by the quadrupole mass spectrometer. 
The Q-AMS can be operated in any of three modes: mass spectrum (MS), particle time-of-flight (PToF), or jump mass spectrum (JMS). In MS mode, the chopper alternates between the beam open and closed positions while the mass spectrometer scans across $m / z 1$ to 300 . Each e.g. five-minute average is the difference between the total open and closed signals and is the ensemble average mass spectrum of thousands of particles. In PToF mode, the beam is chopped and packets of one or a few particles enter the particle sizing region. Particles achieve size-dependent velocities at the exit of the lens which allows measurement of particle size distributions, but only at $\sim 10-15$ selected $\mathrm{m} / \mathrm{z}$ 's. JMS mode is identical to MS mode except in that only $\sim 10 \mathrm{~m} / \mathrm{z}$ 's are monitored to maximize signal-to-noise ratio (SNR) (Crosier et al., 2007; Nemitz et al., 2008). We use the MS mode data for this study because it has high signal-to-noise and contains the full structure of the mass spectra and thus the most chemical information. Each sample is the linear combination of the spectra from all particles and species vaporized during the sample period. If JMS data is available, it may be used to replace the MS $\mathrm{m} / \mathrm{z}$ 's as the JMS data has much better SNR (Crosier et al., 2007). Preliminary analyses show that PToF data contains significant information that can be exploited by PMF-like methods (Nemitz et al., 2008), however this also introduces additional complexities and it is outside of the scope of this paper.

Newer versions of the AMS include the compact timeof-flight mass spectrometer (C-ToF-AMS, Drewnick et al., 2005) and the high-resolution ToF-AMS (HR-ToF-AMS, DeCarlo et al., 2006). These instruments operate in MS and PToF modes. Conceptually the MS mode from the CToF-AMS produces identical data to those from the Q-AMS, except with higher SNR, and thus the results from this paper should be applicable to PMF analyses of such data. The MS mode from the HR-ToF-AMS contains much additional chemical information such as time series of high resolution ions (e.g., both $\mathrm{C}_{3} \mathrm{H}_{7}^{+}$and $\mathrm{C}_{2} \mathrm{H}_{3} \mathrm{O}^{+}$instead of total $\mathrm{m} / \mathrm{z}$ 43) that facilitates the extraction of PMF components. The first application of PMF to HR-ToF-AMS MS-mode data has been presented in a separate publication (Aiken et al., 2009).

The datasets used in this study are comprised of only the organic portion of the AMS mass spectrum measured by the Q-AMS, which is determined from the total mass spectrum by application of a "fragmentation table" (Allan et al., 2004) for removing ions from air and inorganic species. The atomic oxygen to carbon ratio $(\mathrm{O} / \mathrm{C})$ for UMR MS can be estimated from the percent of OA signal at $\mathrm{m} / \mathrm{z} 44$ (predominately $\mathrm{CO}_{2}^{+}$) in the OA MS (Aiken et al., 2008). Percent $\mathrm{m} / \mathrm{z} 44$ is reported here as an indication of the degree of oxygenation of representative spectra.

The time series of inorganic species (non-refractory ammonium, nitrate, sulfate, and chloride) are not included in the PMF analysis and are instead retained for a posteriori comparison with the time series of the factors and for use in their interpretation. It is also of interest to perform the PMF analy- sis on the total spectrum without removing inorganic species (but still removing the large air signals), however this is outside the scope of this paper.

\subsection{Factorization methods}

\subsubsection{Positive Matrix Factorization (PMF)}

Positive Matrix Factorization (PMF) (Paatero and Tapper, 1994; Paatero, 1997) is a model for solving a receptor-only, bilinear unmixing model which assumes that a measured dataset conforms to a mass-balance of a number of constant source profiles (mass spectra for AMS data) contributing varying concentrations over the time of the dataset (time series), such that

$x_{i j}=\sum_{p} g_{i p} f_{p j}+e_{i j}$

where $i$ and $j$ refer to row and column indices in the matrix, respectively, $p$ is the number of factors in the solution, and $x_{i j}$ is an element of the $m x n$ matrix $\mathbf{X}$ of measured data elements to be fit. In AMS data, the $m$ rows of $\mathbf{X}$ are ensemble average mass spectra (MS) of typically tens of thousands of particles measured over each averaging period (typically $5 \mathrm{~min}$ ) and the $n$ columns of $\mathbf{X}$ are the time series (TS) of each $m / z$ sampled. $g_{i j}$ is an element of the $m x p$ matrix $\mathbf{G}$ whose columns are the factor TS, $f_{i j}$ is an element of the pxn matrix $\mathbf{F}$ whose rows are the factor profiles (MS), and $e_{i j}$ is an element of the $m x n$ matrix $\mathbf{E}$ of residuals not fit by the model for each experimental data point $(\mathbf{E}=\mathbf{X}-\mathbf{G F})$. A schematic representation of the factorization is shown in Fig. 1. The model requires no a priori information about the values of $\mathbf{G}$ and $\mathbf{F}$. We normalize the rows in $\mathbf{F}$ (MS) to sum to 1 , giving units of mass concentration $\left(\mu \mathrm{g} / \mathrm{m}^{3}\right)$ to the columns of $\mathbf{G}$ (TS). The values of $\mathbf{G}$ and $\mathbf{F}$ are iteratively fit to the data using a least-squares algorithm, minimizing a quality of fit parameter $Q$, defined as

$Q=\sum_{i=1}^{m} \sum_{j=1}^{n}\left(e_{i j} / \sigma_{i j}\right)^{2}$

where $\sigma_{i j}$ is an element of the $m x n$ matrix of estimated errors (standard deviations) of the points in the data matrix, $\mathbf{X}$. In the "robust mode" of the algorithm, outliers $\left(\left|e_{i j} / \sigma_{i j}\right|>4\right)$ are dynamically reweighted throughout the fitting process so that they cannot pull the fit with weight $>4$. The $Q$-value reported by PMF is calculated using the reduced weights for the outliers. This scaling makes optimal use of the information content of the data by weighing variables by their degree of measurement certainty (Paatero and Tapper, 1994). It is possible that there may be multiple local minima of the $Q$ function (Paatero, 1997); additional solutions can be explored by starting the PMF2 algorithm from different pseudorandom values known as "seeds" within the PMF algorithm. Additionally, the values in $\mathbf{G}$ and $\mathbf{F}$ are constrained to 


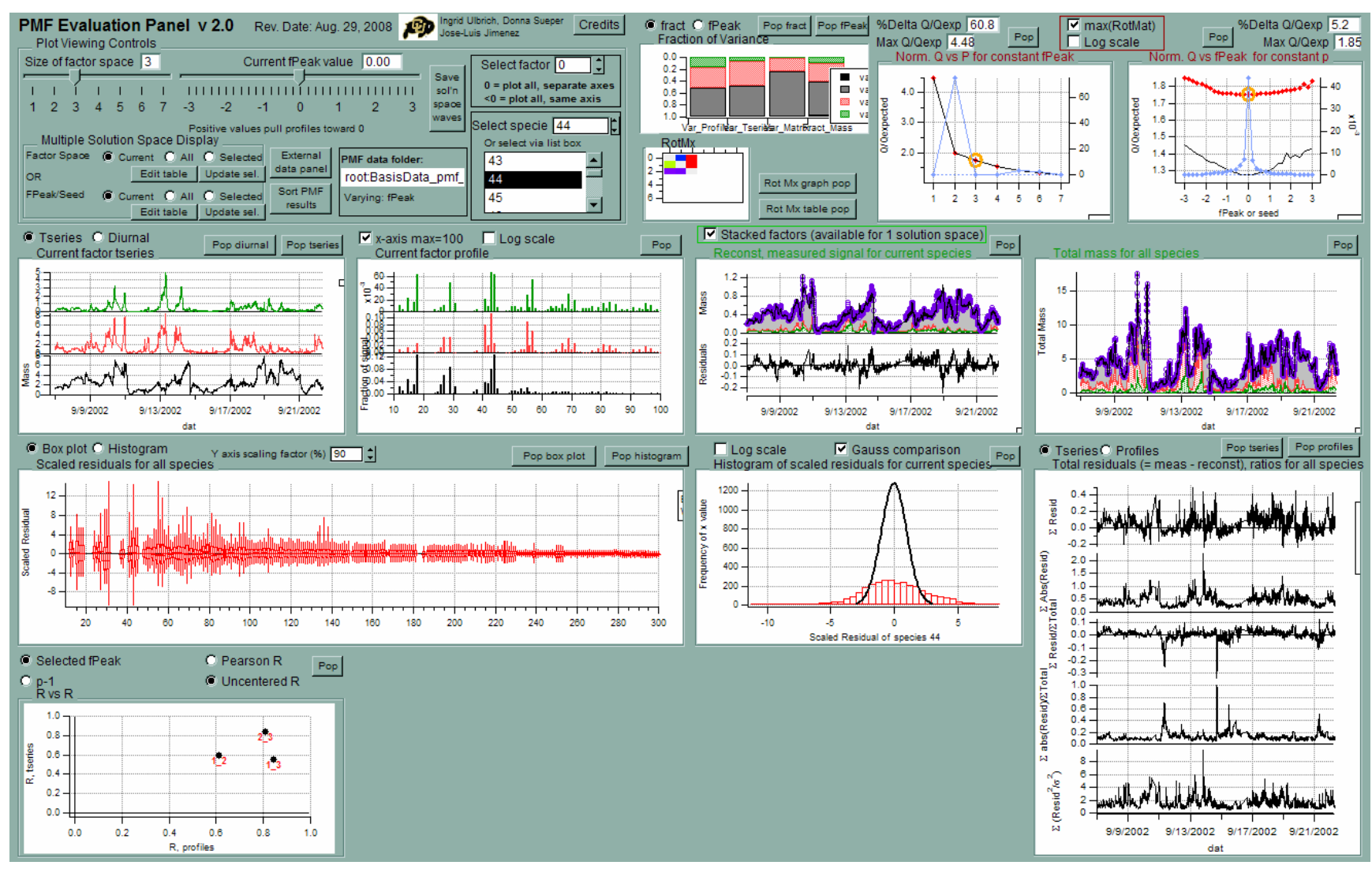

Fig. 2. Screenshot of PMF Evaluation Tool developed for general examination of PMF solutions.

be positive, reflecting positive contributions of each factor to the measured mass and positive signal in each $\mathrm{m} / \mathrm{z}$, respectively.

The bilinear model can be solved by the PMF2 (Paatero, 2007) and multilinear engine (ME) (Paatero, 1999) algorithms developed by P. Paatero, or by custom algorithms developed by others (Lu and Wu, 2004; Lee and Seung, 1999; Hoyer, 2004). Here we use PMF2 because of its robustness and wide use in the research community. Future work will explore more complex models using the ME program. All analyses in this study were done with PMF2 version 4.2 in the robust mode, unless otherwise noted. The default convergence criteria were not modified. Since the output of PMF is very large and evaluating it is very complex, we developed a custom software tool (PMF Evaluation Tool, PET, Fig. 2) in Igor Pro (WaveMetrics, Inc., Portland, Oregon) to evaluate PMF outputs and related statistics. The PET calls the PMF2 algorithm to solve a given problem for a list of values of $p$ and FPEAK or SEED, stores the results for all of these combinations, and allows the user to rapidly display and compare many aspects of the solution matrix and residuals and to systematically evaluate the similarities and differences of the output spectra and time series with known source/component spectra and tracer time series.

\section{Choosing the number of factors}

The number of factors, $p$, in the real dataset is generally unknown. Choosing the best modeled number of factors for a dataset is the most critical decision to the interpretation of the PMF results. Several mathematical metrics have been used to aid determination of this value. A first criterion is the $Q$ value, the total sum of the squares of the scaled residuals. If all points in the matrix are fit to within their expected error, then abs $\left(e_{i j}\right) / \sigma_{i j}$ is $\sim 1$ and the expected $Q$ ( $\left.Q_{\exp }\right)$ equals the degrees of freedom of the fitted data $=m n-p(m+n)$ (Paatero et al., 2002). For AMS datasets, $m n \gg p(m+n)$, so $Q_{\exp } \approx m n$, the number of points in the data matrix. If the assumptions of the bilinear model are appropriate for the problem (data is the sum of variable amounts of components with constant mass spectra) and the estimation of the errors in the input data is accurate, solutions with numbers of factors that give $Q / Q_{\exp }$ near 1 should be obtained. Values of $Q / Q_{\exp } \gg 1$ indicate underestimation of the errors or variability in the factor profiles that cannot be simply modeled as the sum of the given number of components. If $Q / Q_{\exp } \ll 1$, the errors of the input data have been overestimated. As additional factors are considered, $Q$ is expected to decrease, as each additional factor introduces more degrees of freedom 
that should allow more of the data to be fit. A large decrease in $Q$ with the addition of another factor implies that the additional factor has explained significantly more of the variation in the data and has also been used as a metric for choosing a solution (Paatero and Tapper, 1993). A second metric for choosing a best solution is based on the values of the rotational matrix (RotMat, output by PMF and explained below). Some have used the criterion of a solution with the least rotation (lowest maximum value of Rotmat) as one of several qualitative metrics for making the determination of the number of factors (Lee et al., 1999; Lanz et al., 2007). Many studies have concluded that source apportionment models must be combined with supplementary evidence to choose and identify factors (Engel-Cox and Weber, 2007).

Choosing the best number of factors requires the modeler to determine when additional factors fail to explain more of the variability in the dataset. Note that it is possible for one true factor to be mathematically represented by multiple factors which, in total, represent the true factor (Paatero, 2008a). Consider a case in which two true factors make up the data with no error, such that

$\mathbf{X}=\mathbf{G F}$

where $\mathbf{G}=[a b]$, the matrix of the time series of the two factors, and $\mathbf{F}^{T}=[s t]^{T}$, the matrix of the profiles of the two factors, and $a, b, s$, and $t$ are column vectors. If the same dataset $\mathbf{X}$ is solved with three factors, an exact solution could be obtained as

$\mathbf{X}=[e f b] \times[s s t]^{T}$

if $e+f=a$. In fact, a case could be constructed in which two factors reconstruct $b$ instead of $a$, generating a second type of 3-factor solution. More combinations are possible when the same $\mathbf{X}$ created with 2 factors is solved with 4 factors, e.g.,

$\mathbf{X}=[e f b b] \times[s s u v]^{T}$

where $e+f=a$ and $u+v=t$, or

$\mathbf{X}=[$ defb $] \times[s s s t]^{T}$

where $d+e+f=a$. We refer to this type of behavior as "splitting" of the real factors, where either the MS or TS from a real factor are split into two new factors. Linear transformations ("rotations", discussed further in the next section) of these solutions are also possible. A rotation of the threefactor solution shown in Eq. (4) could be represented by

$\mathbf{X}=[e f b] \mathbf{T} \times \mathbf{T}^{-1}[s s t]^{T}$

where $\mathbf{T}$ is a $3 \times 3$ non-singular transformation matrix and $\mathbf{T}^{-1}$ is its inverse and is a valid solution to the PMF model as long as the rotated factor matrices $[e f b] \mathbf{T}$ and $\mathbf{T}^{-1}[s s t]^{T}$ all have positive values. Thus the rotated solutions need not necessarily contain repetitions of the factors from the original solution (Paatero, 2008a). We refer to this later behavior as "mixing" of the real factors.

\section{Rotational ambiguity of solutions}

Despite the constraint of non-negativity, PMF solutions may not be unique, i.e., there may be linear transformations ("rotations") of the factor time series and mass spectra that result in an identical fit to the data, such that:

$\mathbf{G F}=\mathbf{G T T}^{-1} \mathbf{F}$

where $\mathbf{T}$ is a transformation matrix and $\mathbf{T}^{-1}$ is its inverse. A given $t_{i j}>0$ would create a rotation by adding the mass spectra and subtracting the time series of factors $i$ and $j$, while $t_{i j}<0$ would create a rotation by subtracting the mass spectra and adding the time series of factors $i$ and $j$. An infinite number of "rotations" may exist and still meet the non-negativity constraint. Note that orthogonal or "solid body" geometric rotations of the factors are only a subset of the possible linear transformations.

PMF2 does not report the possible values of $\mathbf{T}$, but does report the standard deviation of possible values of $\mathbf{T}$ as the "RotMat" matrix. Larger values in $\mathbf{T}$ imply greater rotational freedom of a solution. Specifically, a larger value of $t_{i j}$ suggests that the $i$ and $j$ factors can be mixed in varying degrees while still satisfying the non-negativity constraint. Diagonal elements of $\mathbf{T}$ are always 1, and their standard deviations are therefore 0 . RotMat for a one-factor solution is always 0 . The value of RotMat as a diagnostic has been debated in the literature (Lanz et al., 2007; Lee et al., 1999; Paatero, 2007), and we explore its use as a qualitative indicator of rotational freedom of a given solution (Sect. 3.1.2, 3.2.2).

With PMF2, once the approximate best number of factors has been determined, a subset of the rotational freedom of the solution may be explored through use of the FPEAK parameter. FPEAK allows for examining approximate or "distorted" rotations that do not strictly follow Eq. (7) and thus produce a higher value of $Q$. Of greatest interest are FPEAK values for which $Q$ does not increase significantly over $Q_{\text {FPEAK }=0}$, since the PMF model (Eq. 2) is still satisfied with little additional error. Some researchers recommend exploring a range of FPEAKs such that $Q / Q_{\exp }$ increases from its minimum by e.g. $10 \%$ (P. K. Hopke, personal communication, 2007). Solutions reported in the literature generally have an FPEAK value between -1 and +1 (Reff et al., 2007). Not all possible rotations can be explored by varying FPEAK, and the characterization of rotations outside of that realm is a topic of current research (Paatero and Hopke, 2008; Paatero et al., 2002). As stated above, none of these metrics or criteria can unequivocally pinpoint the "best" or "true" solution, but a chosen PMF solution can be justified through comparison of factor profiles with known profiles and comparison of factor time series with the time series of tracer species. If several plausible solutions are found, e.g. with different FPEAKs, the differences in the solutions are a good indication of the uncertainty of the PMF solution (Nemitz et al., 2008; Paatero, 2007). 


\section{Uncertainty of the solutions}

The difficult issue of the uncertainty of the solutions is rarely addressed in PMF studies in the literature (Reff et al., 2007). We address this point in this work in two ways: in a qualitative way by running the PMF algorithm from many different random starting points (SEEDs; Paatero, 2007), and quantitatively with bootstrapping with replacement of MS (Norris et al., 2008; Press et al., 2007a).

\subsubsection{Singular value decomposition}

In contrast to PMF, the singular value decomposition (SVD) of a matrix produces only one factorization (as in Eq. 1) with orthogonal factors. Starting with the factor that explains the most variance of the original matrix, factors are retained in order of decreasing variance of the matrix to explain enough (usually 99\%) of the variance of the original matrix. These orthogonal factors usually contain negative values. SVD is applied to selected data matrices and residual matrices to determine the number of factors needed to explain $99 \%$ of the variance of the matrix. The relationship between SVD and PMF is described by Paatero and Tapper (1993).

\subsection{Data sets}

\subsubsection{Real Pittsburgh dataset}

The real Pittsburgh dataset investigated here is the same as that analyzed by Zhang et al. (2005a) with the CPCA method. Versions without pretreatments and with pretreatments applied (filtering for high-noise spikes, 3-point smoothing of $\mathrm{m} / \mathrm{z}$ time series, and use of cluster analysis (Murphy et al., 2003) to remove unusual spectra as described in Zhang et al., 2005a) were analyzed with PMF2. Additional information on the Pittsburgh study can be found in previous publications (Zhang et al., 2004, 2005a, b, c, 2007b). The study took place 7-22 September, 2002 in Pittsburgh, Pennsylvania as part of the Pittsburgh Air Quality Study (PAQS) at the EPA Supersite. 3199 time-averaged mass spectra (5-10 min averaging) were collected for $m / z 1$ to 300 . Fragments with plausible organic fragments were retained, leaving $270 \mathrm{~m} / \mathrm{z}$ fragments. Thirty fragments were removed because they could not have plausible organic fragments, have overwhelming contribution from inorganic or gaseous species, or high instrument background (Zhang et al., 2005a). In addition, organic fragments at $m / z 19$ and 20 are omitted as the signals at these $\mathrm{m} / \mathrm{z}$ 's are directly proportional to $\mathrm{m} / \mathrm{z} 44$ and have negligible contribution $(<0.05 \%$ of the total signal $)$ and therefore do not add new information to the factorization analysis. The remaining matrix had 268 columns $(\mathrm{m} / \mathrm{z})$ and 3199 rows (timeaveraged mass spectra) with 857332 data points.

The error values for use with PMF were calculated in five steps. First, the initial error values were calculated by the method of Allan et al. (2003) by the standard Q-AMS data analysis software (v1.41). We recommend that for Q-AMS data, version 1.41 or later of the standard data analysis software is used for estimation the errors for use with PMF, as corrections to the error calculation algorithms have been made from previous versions and error matrices calculated from earlier versions may give different factors because of different weighting. Nonsensical behavior of the factors (MS with one dominant fragment or TS that oscillate between zero and several $\mu \mathrm{g} / \mathrm{m}^{3}$ over 5-min periods) were observed with this dataset when the error estimates from older versions of the Q-AMS data analysis software, but not when v1.41 was used. Second, a minimum error estimate of one measured ion during the sampling time (equivalent to $11 \mathrm{~Hz}$ or $0.12 \mathrm{ng} / \mathrm{m}^{3}$, which reflects the duty cycle used during this campaign) or the average of the adjacent error values is applied to any elements of the error matrix $\left(\sigma_{i j}\right)$ with values below this threshold by

$\sigma_{i, j}=\max \left(\sigma_{i, j}, \max \left(1 / t_{s},\left(\sigma_{i-1, j}+\sigma_{i+1, j}\right) / 2\right)\right)$

where $t_{s}$ is the time, in seconds, spent sampling each $\mathrm{m} / z$. Third, the 3-point box smoothing applied to the dataset was propagated in the error estimates by summing the error of the 3 smoothed points in quadrature. This has the effect of decreasing the noise estimate by a factor of $\sim \operatorname{sqrt}(3)$. Fourth, we follow the recommendation of Paatero and Hopke (2003) to remove variables (TS of $\mathrm{m} / \mathrm{z}$ in our case) with signal-tonoise ratio (SNR) less than 0.2 ("bad" variables) and downweight variables with SNR between 0.2 and 2 ("weak" variables) by increasing their estimated error values. For this dataset, no columns are "bad" by this definition and 76 of the higher mass fragments $(\mathrm{m} / \mathrm{z}, 167-168,207,210,212,214$, 220-223, 230-238, 240-249, 254-300) are "weak" and their error estimates are increased by a factor of 2 . Finally, in order to appropriately weight $\mathrm{m} / z$ 's $44,18,17$, and 16 (since the latter 3 peaks are related proportionally only to $\mathrm{m} / \mathrm{z} 44$ in the organic "fragmentation table" (Allan et al., 2004) whose inclusion therefore gives additional weight to the strong signal at $m / z 44$ ), the error values for each of these $m / z$ 's are all multiplied by sqrt(4) (N. L. Ng, personal communication, 2008; see Supp. Info.: http://www.atmos-chem-phys.net/9/2891/ 2009/acp-9-2891-2009-supplement.pdf). There are two sets of $\mathrm{m} / \mathrm{z}$ 's that are directly proportional to only one other $\mathrm{m} / \mathrm{z}$ $(\mathrm{m} / \mathrm{z}, 48$ and $\mathrm{m} / \mathrm{z} 62 ; \mathrm{m} / \mathrm{z} 80$ and $\mathrm{m} / \mathrm{z} 94)$, but these signals are much smaller than those of the $\mathrm{m} / z 44$-group and the effect of this adjustment is negligible. Note that the order of steps four and five are arbitrary; even after changing the error estimates for $m / z$ 's 44, 18, 17, and 16 their SNR's are approximately 25 and they are not "weak" variables. The downweighting of so many $m / z$ 's in the datasets lowers the calculated $Q$-values; $Q / Q_{\text {exp-values reported in this work have therefore been re- }}$ calculated by undoing this scaling (but still applying the robust criterion) so that $Q / Q_{\text {exp }}$-values are related to the error estimated for each point from the data prior to downweighting. 
No adjustments are made to the errors in this analysis to reflect "model error" that may occur because the true factors are not constant as assumed by the PMF model. Increasing the error values to reflect this error may downweight real phenomena that are part of the true data. Note that small negative values that are the result of differences (caused by noise) between the beam open and beam closed measurements in the instrument data are not changed, nor are their corresponding error values altered.

\subsubsection{Synthetic datasets}

Each synthetic dataset was created by combining selected MS and TS into $\mathbf{F}_{\text {input }}$ and $\mathbf{G}_{\text {input }}$ matrices, respectively, which were then multiplied to form an $\mathbf{X}_{\text {input }}$ matrix $\left(\mathbf{X}_{\text {input }}=\mathbf{G}_{\text {input }} \times \mathbf{F}_{\text {input }}\right.$, the forward calculation of Eq. (1) with $e_{i j}=0$ ).

Synthetic noise was added to the difference spectrum synthetic data, such that the noisy synthetic data, $x^{\prime}$ were calculated by

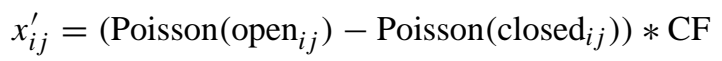

+ Gaussian $(0,0.0002)$

where random noise is generated from a Poisson random number generator (Igor Pro v6.03) with a mean and variance of the number of ions observed in the open and closed MS of that point (open $_{i j}$ and $\operatorname{closed}_{i j}$, respectively), CF is the conversion factor from ions per $\mathrm{m} / \mathrm{z}$ per averaging period to $\mu \mathrm{g} / \mathrm{m}^{3}$, and electronic noise is estimated from a normal Gaussian distribution with a standard deviation of $0.0002 \mu \mathrm{g} / \mathrm{m}^{3}$. The amount of $0.0002 \mu \mathrm{g} / \mathrm{m}^{3}$ is an estimate of the electronic noise present during periods of low signal in several $\mathrm{m} / \mathrm{z}$ 's $>239$. Poisson noise is used for ion counting noise instead of Gaussian noise because many of the small signals do not have sufficient counts to reach a Gaussian distribution to a good approximation. The sum of ion counting and electronic noises represents most of the noise in a QAMS dataset, but does not reflect "particle-counting statistics noise" from events when a large particle is vaporized and "extra" (much greater than average) signal is detected at only one $m / z$ during the scanning of the quadrupole across the $\mathrm{m} / \mathrm{z}$ range (Zhang et al., 2005a).

The synthetic Poisson-distributed error values for these datasets were approximated by a method parallel to the estimation of errors for real data (see description in Appendix A). The real and synthetic errors are similar, and thus the synthetic datasets retain the error structure of the real data. The treatments described in Sect. 2.3.1 (above) for applying a minimum error threshold, downweighting "weak" variables, and weighting $m / z$ 's related to $m / z 44$ were also applied to the error estimates for the synthetic datasets. No error propagation for box smoothing is applied to the synthetic data because these data are not smoothed. The SNR for the $\mathrm{m} / \mathrm{z}$ 's in the synthetic datasets are therefore higher by a factor of $\sim$ sqrt(3), and there are more "weak" variables $(84 \mathrm{~m} / z$ 's total) than in the real data. The weak $m / z$ 's in the synthetic datasets include the same $\mathrm{m} / \mathrm{z}$ 's as in the real dataset, as well as $m / z$ 's 150,185 (2-factor case only), 216, 227, 239 (3-factor case only), and 250-253.

\section{Two-factor synthetic dataset}

A two-factor synthetic base case was created using the HOA and OOA MS and TS as determined by Zhang et al. (2005a, c) for the Pittsburgh dataset. Difference spectra may contain negative values for very small signals, akin to belowdetection limit values in other datasets. Zhang et al. (2005a) allowed their method to fit these small negative values and the resulting factors include small negative numbers. Negative values in the Zhang solution were converted to their absolute value before creating the $\mathbf{F}_{\text {input }}$ and $\mathbf{G}_{\text {input }}$ matrices, so that the input has only positive numbers. The resultant increase in signal is much smaller than the residual from the Zhang factorization and does not affect the results of the PMF factorization.

\section{Three-factor synthetic datasets}

A three-factor synthetic base case was created from the threefactor PMF solution with FPEAK=0 of the real Pittsburgh dataset (described below). All factor elements were positive for this solution, so no treatment of negative values was necessary.

Variations on the three-factor base case were made to explore the ability of PMF to retrieve factors which have a small fraction of the total mass. Three-factor synthetic cases were created by replacing the mass spectrum of the smallest factor in the previous three-factor synthetic case with reference mass spectra (see Sect. 2.4.1) of fulvic acid (FA) (Alfarra, 2004), biomass burning organic aerosol (BBOA, Palmetto leaf smoke from the Fire Lab at Montana Experiment (FLAME-1) in June 2006), or fresh chamber SOA (methylene cyclohexane $+\mathrm{O}_{3}$, Bahreini et al., 2005), each of which has a different correlation to the other MS in the input. Variations on this case were made in which the average mass of this factor was decreased (cases with $11.4 \%, 5.7 \%, 2.9 \%$, $1.4 \%$, and $0.7 \%$ average mass fraction) and used in a new $\mathbf{G}_{\text {input }}$ to create a new $\mathbf{X}_{\text {input }}$.

\subsection{Statistical comparisons of mass spectra}

\subsubsection{Reference spectra}

An AMS Spectral Database (Ulbrich et al., 2007) has been created to collect published AMS spectra for public use. AMS spectra are similar, but not identical to, spectra from standard electron-impact databases such as the NIST Chemistry WebBook (http://webbook.nist.gov/chemistry/, Stein et al., 2001), primarily because of thermal decomposition of molecules during vaporization in the AMS and additional 
thermal energy of the ions leading to increased fragmentation (Alfarra, 2004; Dzepina et al., 2007). Different AMS instruments operating with the same vaporizer temperature produce similar spectra (Alfarra, 2004; Dzepina et al., 2007). These reference spectra are used to aid the identification of spectra in PMF factors. The database contains spectra for several categories of aerosol, including ambient aerosol, direct measurements from sources (e.g., vehicles, biomass burning), laboratory-generated aerosol of chemical standards, laboratory SOA, laboratory heterogeneously oxidized particles, other laboratory-generated aerosol, and spectra derived from mathematical deconvolutions of ambient OA. Organic aerosol spectra in the database span a range of representative hydrocarbon-like (e.g., diesel bus exhaust, fuel, and lubricating oil) and oxygenated (e.g., various chamber SOA, oxalic acid, and fulvic acid) OA.

\subsubsection{Statistics of correlation}

Throughout this work we report "uncentered" correlations between MS and TS as a qualitative metric to support factor identification and compare factors amongst different PMF solutions (Paatero, 2008a). The uncentered correlation coefficient (UC) reports the cosine of the angle between a pair of MS or TS as vectors, such that

$\mathrm{UC}=\cos \theta=\frac{\boldsymbol{x} \cdot \boldsymbol{y}}{\|\boldsymbol{x}\|\|\boldsymbol{y}\|}$

where $\boldsymbol{x}$ and $\boldsymbol{y}$ denote a pair of MS or TS as vectors. The uncentered correlation is very similar to the well-known Pearson $R$ for mass spectra, and quite correlated with Pearson's $R$ for time series (when computed with a large number of different MS and TS; see Fig. S1, see http://www.atmos-chem-phys.net/9/2891/2009/ acp-9-2891-2009-supplement.pdf). Correlations between MS are complicated because the signal values span several orders of magnitude and a few high intensity masses (generally all at $m / z \leq 44$ ) can dominate the correlation (Hemann et al., 2009). For correlations between factor and reference MS, we also report UC for $m / z>44$ to remove this bias (Alfarra et al., 2006, 2007; Lanz et al., 2007). These two statistics represent one way to numerically match factor profiles to reference profiles for AMS datasets and improve the source identification process (as suggested by Reff et al., 2007). A rank-correlation method, Spearman $R$, in which correlations are made using the rank order of values (highest $=n$, lowest=1) instead of the actual data values (Press et al., 2007b), was also considered as well as several variations on it (e.g., removing ions with low signal in both spectra before calculation), but this often gave too much weight to small signals and otherwise did not aid interpretation beyond that provided by UC for $m / z>44$. Correlations are presented in the text as $\mathrm{UC}_{\mathrm{HOA}}^{\mathrm{TS}}$ in, $\mathrm{HOA}$ out, $\mathrm{UC}_{\mathrm{HOA}}^{\mathrm{MS}}$ in, $\mathrm{HOA}$ out, and $\mathrm{UC}_{\mathrm{HOA}}^{\mathrm{MS}, \mathrm{m} / \mathrm{z}, \mathrm{HOA} \text { out }}$, where the superscript describes whether MS or TS are being compared (using only $m / z$ 's $>44$ when specified) and the subscript describes what data are being compared (here, the input HOA and output HOA for a synthetic dataset). Correlations are calculated using only the points common to both vectors being correlated; e.g., MS from the AMS Spectral Database may have $300 \mathrm{~m} / z$ while factor MS have only the $268 \mathrm{~m} / \mathrm{z}$ 's that were retained, thus missing $\mathrm{m} / \mathrm{z}$ values are omitted from the vectors before calculating the correlations; TS from different instruments may be missing different periods of data, thus only the points when both instruments report data are included.

\section{Results}

\subsection{Real Pittsburgh data}

We explored the effect of data pretreatment (Zhang et al., 2005a), downweighting of "weak" variables by a factor of 2 (Paatero and Hopke, 2003), and use of the robust mode in PMF. Differences in the factor MS and TS were minor in all cases for this dataset. Comparisons of the 3-factor solutions from the robust and non-robust modes are shown in Fig. S2, see http://www.atmos-chem-phys.net/9/2891/2009/ acp-9-2891-2009-supplement.pdf. We note, however, that this dataset has good SNR, that pretreatment aids the analysis by removing spikes whose cause is understood (poor sampling statistics of high-mass, low-number particles mainly in HOA $\mathrm{m} / \mathrm{z}$ 's, Zhang et al., 2005a), and that these techniques can make a bigger difference for a dataset with much lower signal-to-noise (Canagaratna et al., 2006). We report results for the case with pretreatment, with downweighting, and in the robust mode in order to capture the broad characteristics of the dataset. Throughout this section, a "case" refers to an input dataset and a "solution" refers to PMF2 results.

\subsubsection{Solutions as a function of number of factors}

$Q$-values and maximum value of RotMat for the real Pittsburgh dataset for solutions up to 7 factors are shown in Fig. $3 \mathrm{a}$ and mass fractions of these solutions are shown in Fig. 4a, all for FPEAK=0. There is a large drop in the $Q / Q_{\exp }$ value from one to two factors, and $Q / Q_{\exp }$ is 1.9 at 2 factors. Additional factors continue to reduce $Q / Q_{\exp }$ toward 1, but no strong change in slope is observed (largest steps are 9\% from 2-3 factors and 4-5 factors). With seven factors, $Q / Q_{\exp }$ is 1.3 . The $Q$ criterion clearly implies that at least two factors are necessary to explain the data, but there is no strong indication for choosing another solution. Max(RotMat) has a distinct maximum at 2 factors and much smaller values for larger numbers of factors. There is a local minimum at 3 factors and another at 7 factors (confirmed by solutions with $>7$ factors). Based on the trends of $Q / Q_{\exp }$ and the max(RotMat) from Lee et al. (1999), solutions with 2 or more factors would be suitable. SVD analysis of the data matrix shows that 3 factors are required to explain at least $99 \%$ of the variance (Fig. 3d). We proceed to analyze 

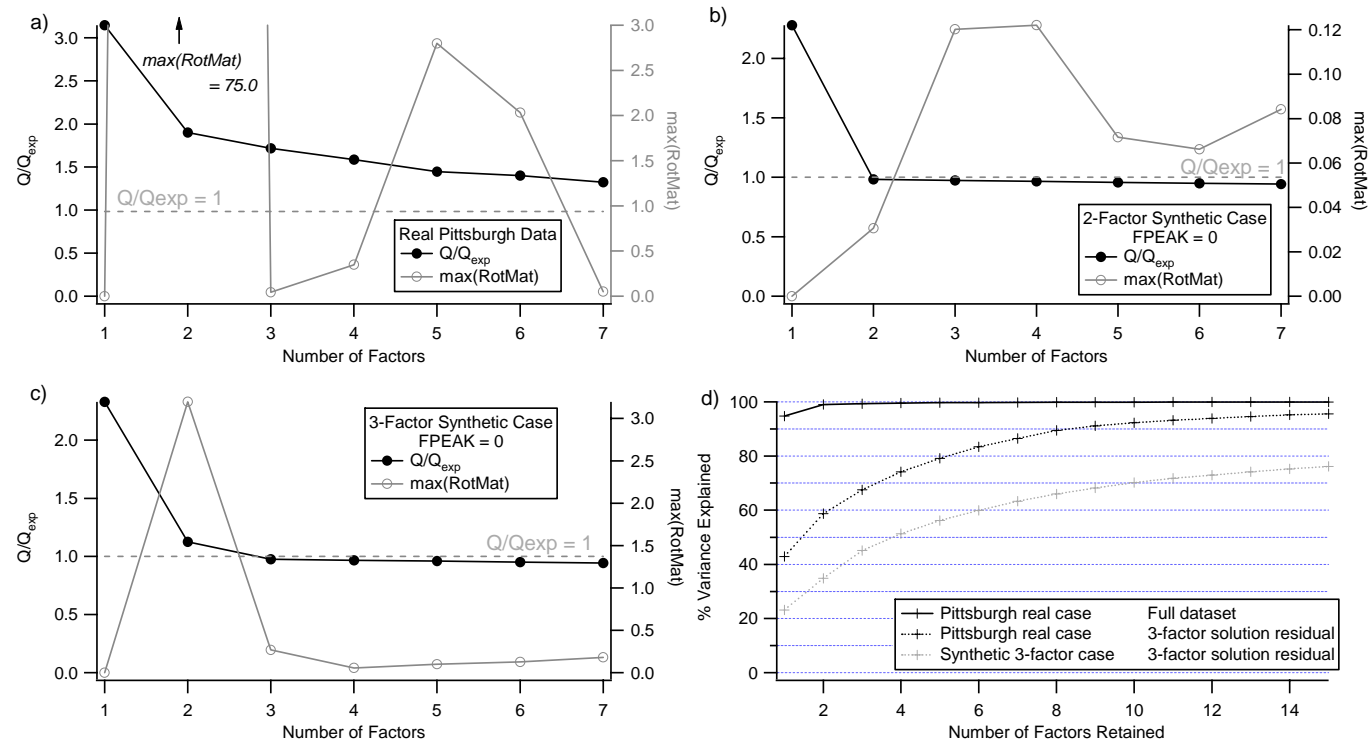

Fig. 3. Values of $Q / Q_{\text {exp }}$ and the maximum value of RotMat for (a) the real Pittsburgh case, (b) the two-factor synthetic case, and (c) the three-factor synthetic case. (d) Percent variance explained by factors from SVD analysis of the Pittsburgh real data matrix and the residual matrices from the Pittsburgh real case solution with 3 factors and the synthetic 3-factor base case solution with 3 factors.
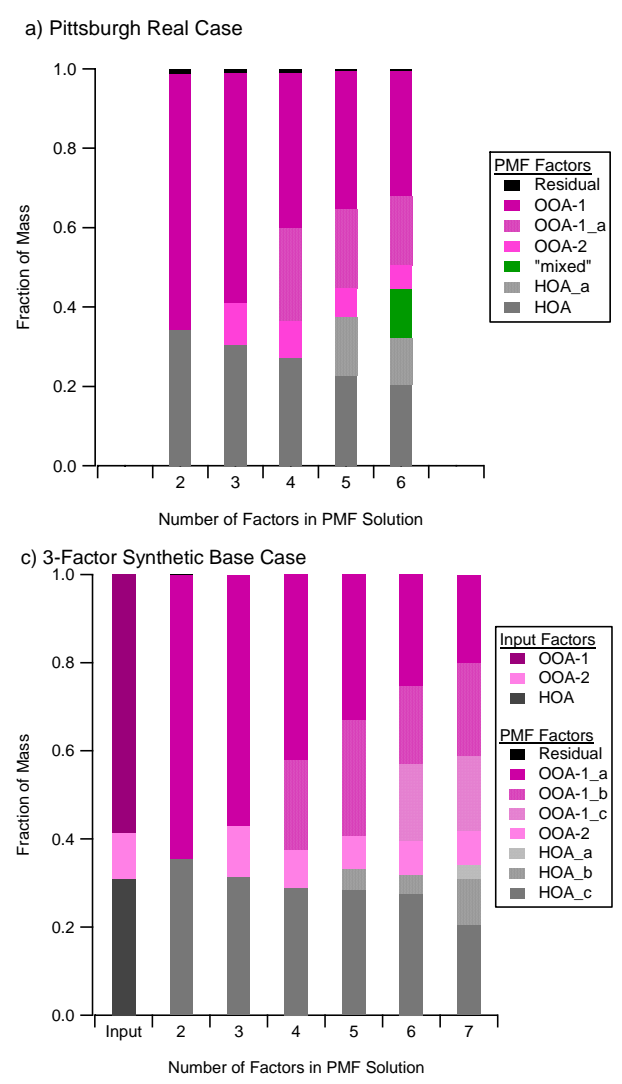

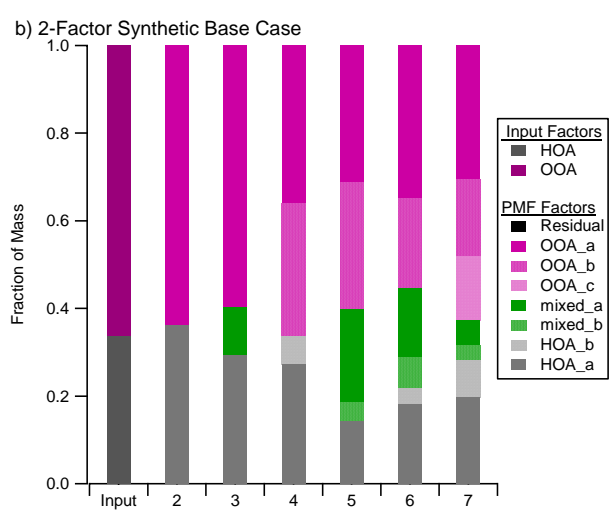

Number of Factors in PMF Solution

Fig. 4. Mass fraction of each factor in solutions from 2 to 7 factors for (a) the real Pittsburgh case, (b) the two-component synthetic dataset, and (c) the three-component synthetic dataset. 
each solution stepwise and attempt to interpret them based on correlations with reference MS and tracer TS and use this interpretability as a guide for choosing the number of factors.

\section{2-factor solution}

The MS and TS of the two-factor solution are shown in Fig. S3a, see http://www.atmos-chem-phys.net/9/2891/ 2009/acp-9-2891-2009-supplement.pdf. These two factors reproduce the MS and TS found by Zhang et al. (2005a) for this dataset using their original 2-component CPCA method $\left(\mathrm{UC}_{\mathrm{HOA}}^{\mathrm{MS}}\right.$ Zhang, $\mathrm{HOA}$ PMF $=0.98, \mathrm{UC}_{\mathrm{OOA}}^{\mathrm{MS}}$ Zhang, OOA PMF $>0.99$,

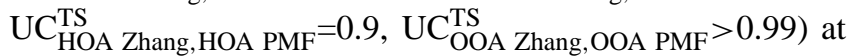
FPEAK $=0$. The OOA factor has $12 \% \mathrm{~m} / \mathrm{z} 44$ and the HOA factor has $3 \% \mathrm{~m} / \mathrm{z} 44$ at FPEAK $=0$. All interpretations of the factors made by Zhang et al. (2005a, c) hold for these factors.

\section{3-factor solution}

The MS and TS of the three factor solution at FPEAK $=0$ are shown in Fig. 5 (correlations between selected PMF and tracer TS are shown in Table S1, see http://www.atmos-chem-phys.net/9/2891/2009/ acp-9-2891-2009-supplement.pdf). The three-factor solution has HOA and OOA factors very similar to the Zhang et al. (2005a) HOA and OOA ( $\mathrm{UC}_{\mathrm{HOA}}^{\mathrm{MS}} \mathrm{Zhang}, \mathrm{HOA}$ PMF $=0.97$,

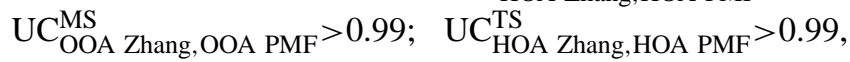
$\mathrm{UC}_{\mathrm{OOA}}^{\mathrm{TS}}$ Zhang, $\left.\mathrm{OOA} \mathrm{PMF}=0.98\right)$ that correlate well with primary combustion tracers $\left(\mathrm{UC}_{\mathrm{CO}, \mathrm{HOA}}^{\mathrm{TS}}=0.93, \quad \mathrm{UC}_{\mathrm{NO}_{\mathrm{x}}, \mathrm{HOA}}^{\mathrm{TS}}=0.95\right)$ and AMS sulfate $\left(\mathrm{UC}_{\text {Sulfate, } \mathrm{OOA}}^{\mathrm{TS}}=0.95\right)$, respectively. Note that HOA likely encompasses both gasoline and diesel engine emissions, plus other sources of reduced aerosols such as meat cooking (Mohr et al., 2009). PMF analysis of molecular markers results in a similar phenomenon in which the composition of gasoline and diesel emissions are too similar and a factor representing the sum is often retrieved (Brinkman et al., 2006).

The third factor represents $10 \%$ of the OA mass and has a MS with strong correlation with several primary, secondary, and biomass burning OA spectra from the AMS Spectral Database (Figs. 6a, S4a, Table S2, see http://www.atmos-chem-phys.net/9/2891/2009/ acp-9-2891-2009-supplement.pdf). We identify this spectrum as a second type of OOA, OOA-2, because of the strong presence of $\mathrm{m} / \mathrm{z} 44$ (high resolution aerosol mass spectrometer data of ambient aerosols confirm that this is most likely $\mathrm{CO}_{2}^{+}$, DeCarlo et al., 2006; Huffman et al., 2009), and the correlation with OOA/SOA spectra. The OOA that accounts for most of the mass is very similar to that identified by Zhang et al. (2005a) and Lanz et al. (2007) and is termed OOA-1, following the nomenclature of Lanz et al. (2007). The OOA-2 spectrum lies 23 degrees out of the HOA/OOA-1 plane (calculation described in Supp. Info, see http://www.atmos-chem-phys.net/9/2891/ 2009/acp-9-2891-2009-supplement.pdf), is clearly not a linear combination of the HOA and OOA-1 spectra, and is unlikely to arise due to noise. The lack of significant $\mathrm{m} / \mathrm{z}$ 's 60 and 73 strongly suggests that this OOA-2 does not arise from a biomass burning source (Alfarra et al., 2007; Schneider et al., 2006). The OOA-2 time series correlates well with ammonium nitrate and ammonium chloride from the AMS, two secondary inorganic species which were not included in the PMF analysis $\left(\mathrm{UC}_{\mathrm{Ammonium} \text { Nitrate, } \mathrm{OOA}-2}^{\mathrm{TS}}=0.79\right.$, $\mathrm{UC}_{\text {Ammonium Chloride, } \mathrm{OOA}-2}^{\mathrm{TS}}=0.82$; diurnal cycles are shown in Fig. S5, see http://www.atmos-chem-phys.net/9/2891/ 2009/acp-9-2891-2009-supplement.pdf). Note that we can confirm that nitrate and chloride signals from the AMS in this study are indeed dominated by the inorganic ammonium salts, not fragments of organic species, based on the ammonium balance (Zhang et al., 2005b, 2007b). The OOA-2 factor is less-oxygenated than OOA-1 and more oxygenated than HOA $(\mathrm{m} / \mathrm{z} 44$ of OOA-1 is $12.5 \%$, of OOA2 is $6 \%$, and of HOA is $2.5 \%$ ). Since both nitrate and chloride show a semivolatile behavior in Pittsburgh (Zhang et al., 2005b), these correlations imply that OOA-2 is also semivolatile. Most likely OOA-2 corresponds to less oxidized, semivolatile SOA, while OOA-1 likely represents a more aged SOA that is much less volatile. Direct volatility measurements with a thermal-denuder AMS combination indeed show that in Mexico City and Riverside, CA, the less oxygenated OOA-2 component is more volatile than the OOA-1 component (Huffman et al., 2009). A similar OOA-2 factor with a less oxidized spectrum and a high correlation with nitrate was reported by Lanz et al. (2007) for their dataset in Zurich in summer of 2005, though the ratios of OOA-2 to nitrate differ $(\sim 1$ in the present work, $\sim 2$ in Zurich). These authors also interpreted OOA-2 as fresh SOA. No evidence is available to support the identification of OOA-1 or OOA-2 as either "anthropogenic" or "biogenic" in origin.

\section{4-factor solution}

The TS and MS for the 4-factor solution are shown in Fig. S3b, see http://www.atmos-chem-phys.net/ 9/2891/2009/acp-9-2891-2009-supplement.pdf. The four-factor solution has clear HOA, OOA-1, and OOA-2 factors with high similarity to those in the 3 -factor case $\quad\left(\mathrm{UC}_{3-\text { factor OOA-1,4-factor OOA-1 }}^{\mathrm{TS}}=0.96\right.$,

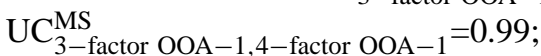

$\mathrm{UC}_{3-\text { factor OOA-2,4-factor OOA-2, }}^{\mathrm{TS}}$,

$\mathrm{UC}_{3-\text { factor OOA-2,4-factor OOA-2 }}^{\mathrm{MS}}>0.99$;

$\mathrm{UC}_{3-\text { factor HOA,4-factor HOA, }}^{\mathrm{TS}}$,

$\mathrm{UC}_{3-\text { factor HOA,4-factor HOA }}^{\mathrm{MS}}>0.99$ ) which are interpreted as in the 3-factor case. The fourth factor correlates well with sulfate $\left(\mathrm{UC}_{\text {Sulphate, } 4-\text { factor Unnamed }}^{\mathrm{TS}}=0.84\right)$ and has a similar mass fraction as OOA-1 (39\% and $24 \%$, respectively). The MS of the fourth factor has 

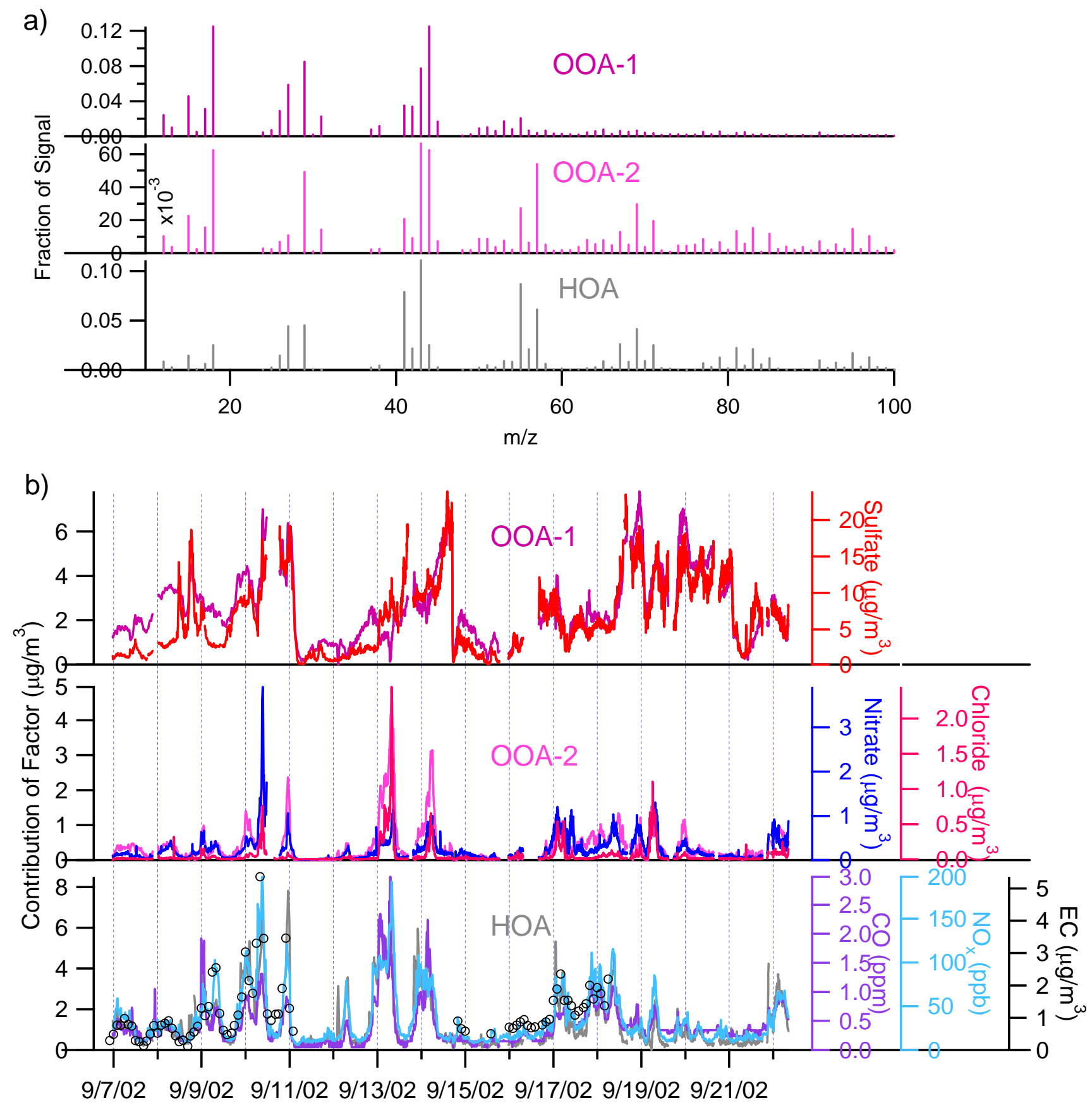

Fig. 5. Factors from the three-component PMF solution of the real Pittsburgh dataset for FPEAK=0. (a) Mass spectra of the three components. The fraction of the signal above $\mathrm{m} / \mathrm{z} 100$ is $3.4 \%, 24.3 \%$, and $9.7 \%$ for OOA-1, OOA-2, and HOA, respectively. (b) Time series of the three components and tracers.

$\mathrm{UC}_{\text {database spectra,4-factor Unnamed }}^{\mathrm{MS}}>0.8$ with database mass spectra of the Zhang Pittsburgh OOA, three types of SOA, and four types of biomass burning (Figs. 6b, S4b, Table S2, see http://www.atmos-chem-phys.net/9/2891/ 2009/acp-9-2891-2009-supplement.pdf). However, strong independent evidence (such as a strong tracer correlation) for a distinctive, separate component is not present. This additional component shows many (but not all) of the signs of the "component splitting" of the solutions of the synthetic data cases discussed below (Sect. 3.2.1). In addition, the analysis of the residuals (below) does not suggest that adding components after the first 3 fits more of the data. Thus in the 


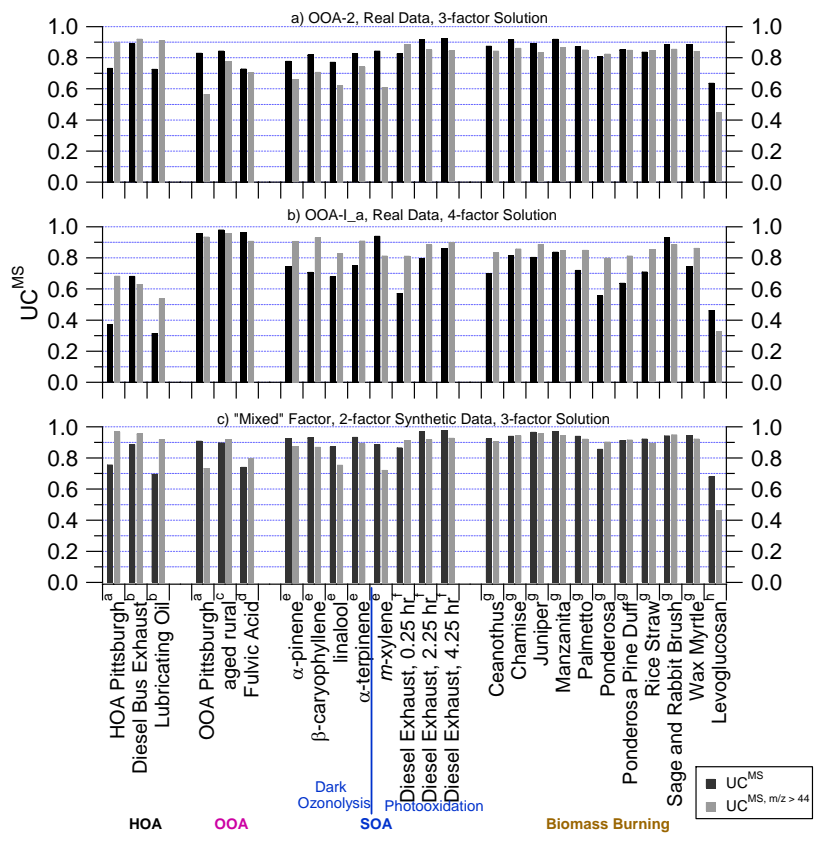

Fig. 6. $\mathrm{UC}^{\mathrm{MS}}$ between representative spectra from the AMS Mass Spectral Database (http://cires.colorado.edu/jimenez-group/ AMSsd) and (a) the third factor mass spectrum from the 3 -factor PMF solution of the real Pittsburgh dataset, (b) the fourth factor mass spectrum from the 4-factor PMF solution of the real Pittsburgh dataset, and (c) the "mixed" factor mass spectrum from the 3-factor PMF solution of 2-factor base case. Values are given in Table S1 (see http://www.atmos-chem-phys.net/9/2891/2009/ acp-9-2891-2009-supplement.pdf). Superscripts denote the source of the reference spectra as follows: (a) Zhang et al., 2005a; (b) Canagaratna et al., 2004; (c) Alfarra et al., 2004; (d) Alfarra, 2004; (e) Bahreini et al., 2005; (f) Sage et al., 2007; (g) I. M. Ulbrich, J. Kroll, J. A. Huffman, T. Onash, A. Trimborn, J. L. Jimenez, unpublished spectra, FLAME-I, Missoula, MT, 2006; (h) Schneider et al., 2006.

absence of any supporting evidence, we concluded that this component represents an artificial "splitting" of the solution (calling this factor OOA-1a) and that keeping this component would be an overinterpretation of the PMF results. In particular we warn about trying to interpret e.g. one of the OOA-1's as "biogenic" and the other as "anthropogenic" or similar splits, in the absence of strong evidence to support these assignments.

\section{Five and more factor solutions}

The five-factor solution (Fig. S3c, see http: //www.atmos-chem-phys.net/9/2891/2009/ acp-9-2891-2009-supplement.pdf) has four factors that are similar (OOA-1, OOA-1a, OOA-2, HOA) $\left(\mathrm{UC}_{4-\text { factor,5-factor }}^{\mathrm{TS}}>0.96, \quad \mathrm{UC}_{4-\text { factor,5-factor }}^{\mathrm{MS}}>0.90\right)$ to the factors in the 4-factor solution. The fifth factor (HOA_a) is similar to the HOA factor in this solution $\quad\left(\mathrm{UC}_{5-\text { factor HOA,5-factor HOA_a }}^{\mathrm{MS}}=0.85\right.$, $\left.\mathrm{UC}_{5-\text { factor HOA,5-factor HOA_a }}^{\mathrm{TS}}=0.68\right)$ and has $\mathrm{UC}_{\text {Database Spectra,5-factor HOA_a }}^{\mathrm{MS}}>0.8$ with five types of SOA and eight types of BBOA, but there is no strong correlation with any available tracer. The HOA and HOA_a factors have $23 \%$ and $15 \%$ of the mass, respectively. As before, we conclude that this "splitting" of the HOA is most likely a mathematical artifact and not a real component.

Interpretation of factors in the six- and seven-factor solutions becomes more complex and no independent information from tracer correlations exists to substantiate the interpretation of these factors. These factors likely arise due to splitting of the real factors, likely triggered by variations in the spectra of the real components (discussed below).

\section{Uncertainty of the solutions of real data}

In order to explore the possibility of multiple local minima in the solutions of the dataset and qualitatively assess variability in the factors, trials with 64 multiple starts were calculated for the real Pittsburgh case with solutions up to 6 factors. Local minima can be identified by solutions with different $Q / Q_{\exp }$ values, but this is not a sufficient criterion as it could be possible for two local minima to have similar $Q / Q_{\exp }$ values with different factors; therefore similarity of the factor MS and TS is also considered as a criterion for determining local minima. In the solutions with 2- to 6-factors, no local solutions were observed. The 3-factor solutions show the greatest variation in $Q / Q_{\exp }$ values, which however increase by only $2 \times 10^{-4} Q / Q_{\exp }$ units above the minimum. There are two modes of the solutions in this small range, defined by the ratio of $m / z 43: m / z 44$ in the MS of the OOA-2 factor, while the MS of the OOA-1 factor varies little and the MS of the HOA factor is virtually identical in all solutions. The TS of all of these solutions are virtually identical (the overlaid TS and MS of all 64 solutions for the 3-5 factor solutions are shown in Fig. S6, see http://www.atmos-chem-phys.net/ 9/2891/2009/acp-9-2891-2009-supplement.pdf).

Quantitative assessment of the uncertainty of the factors is made by 100 bootstrapping runs (Norris et al., 2008) of which 95 reproduce all three factors. The average factor MS and TS along with $1 \sigma$ variation bars for each point are shown in Fig. S7, see http://www.atmos-chem-phys.net/9/ 2891/2009/acp-9-2891-2009-supplement.pdf. These results show that the uncertainty in the TS of the three components is small, as it is for the MS of HOA and OOA-1. The MS of OOA-2 shows some uncertainty, which is nevertheless small compared to the general structure of the spectrum. Thus we conclude that the results reported here are robust and that their statistical uncertainties are small. 


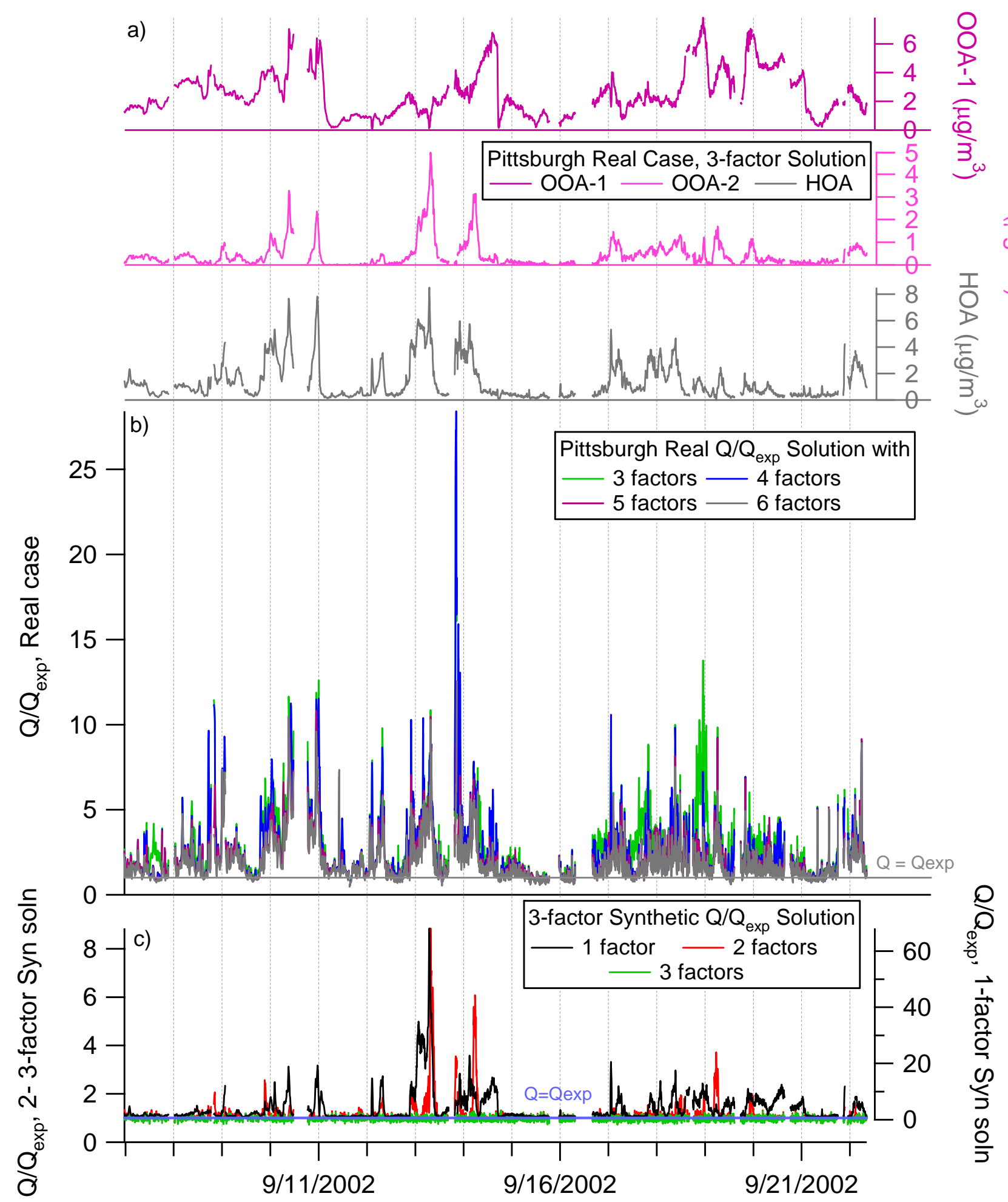

Fig. 7. (a) OOA-1, OOA-2, and HOA time series from the 3-factor solution of the real Pittsburgh dataset. (b) $Q / Q$ exp-contribution of each sample from the 3- to 6-factor solutions of the real Pittsburgh dataset. (c) $Q / Q$ exp-contribution of each sample for the 1- to 3-factor solutions of the synthetic 3 -factor base case. 

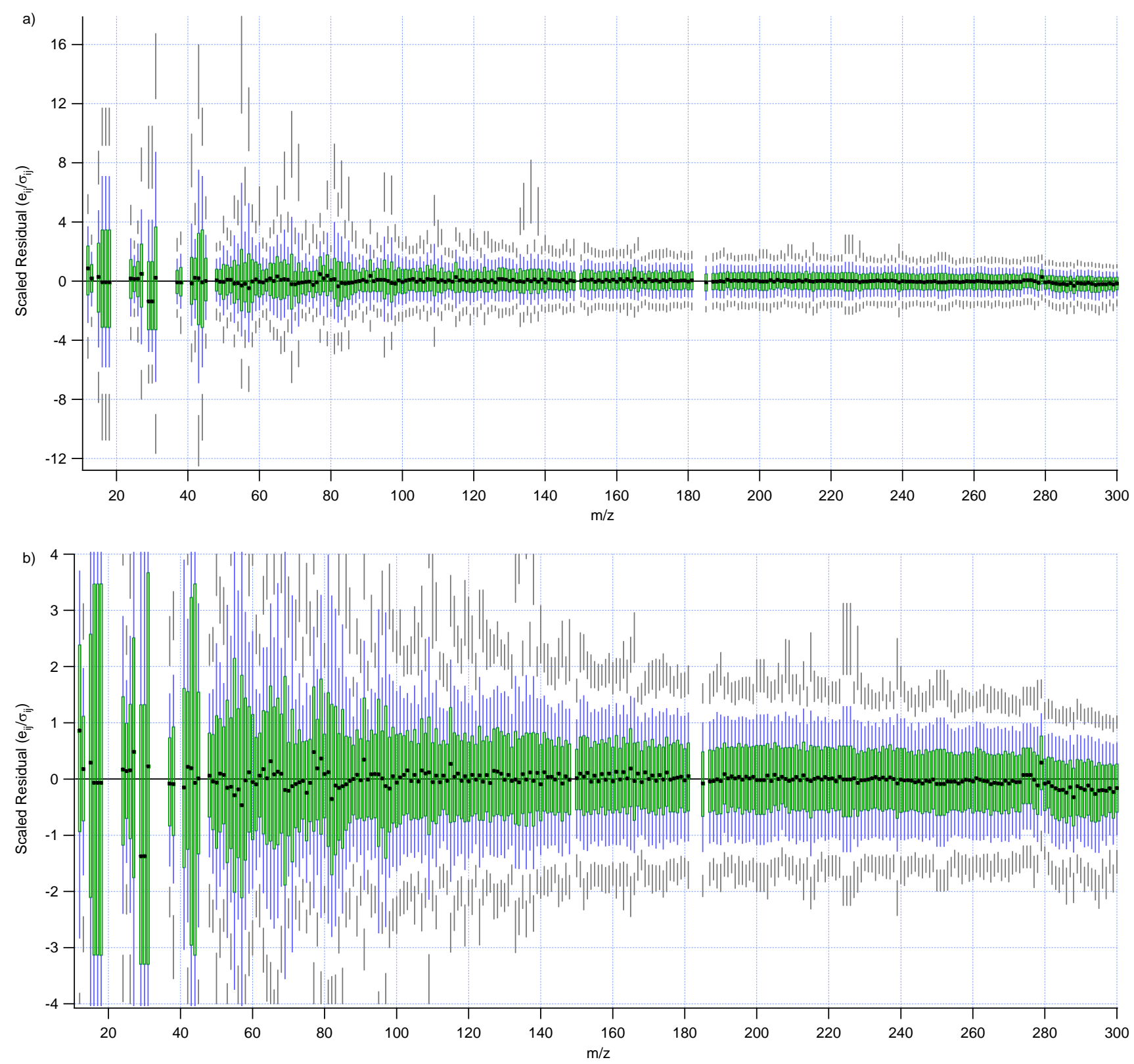

Fig. 8. (a) Distributions of scaled residuals for each $\mathrm{m} / \mathrm{z}$ for the 3 -factor solution of the real Pittsburgh case. Black markers represent medians. Green boxes span the 25th and 75th percentiles; blue whiskers attached to the boxes extend to 10th and 90th percentiles. Grey "floating" whiskers connect 2 nd to 5 th percentiles and 95 th to 98 th percentiles. (b) Expansion of (a) showing the scaled residuals from -4 to 4.

\section{Residuals of the PMF solutions}

Figure 7 shows the $Q / Q_{\exp }$ values for each point in time and Fig. S8 shows the total residuals ( $\Sigma$ residual), total absolute residuals $(\Sigma \mid$ residual $\mid)$, and normalized absolute residuals $(\Sigma \mid$ residual $\mid / \Sigma$ signal $\mid)$ for the 3- through 6factor solutions for FPEAK $=0$. Note that $Q_{\exp }$ for a time sample equals the number of $m / z$ 's in the MS (268). Figure 8 shows a summary distribution of the scaled residuals for all $\mathrm{m} / \mathrm{z}$ from the real Pittsburgh data and Fig. S9 shows the distribution of the scaled residuals for selected $\mathrm{m} / \mathrm{z}$ 's (see http://www.atmos-chem-phys.net/9/ 2891/2009/acp-9-2891-2009-supplement.pdf); minimization of total $Q$ (squared scaled residuals) while meeting non-negativity constraints drives the solutions of the PMF algorithm. The contributions to both $Q / Q_{\exp }$ and absolute residual, even after fitting 3 to 6 factors, have considerable structure (above a background level) that 


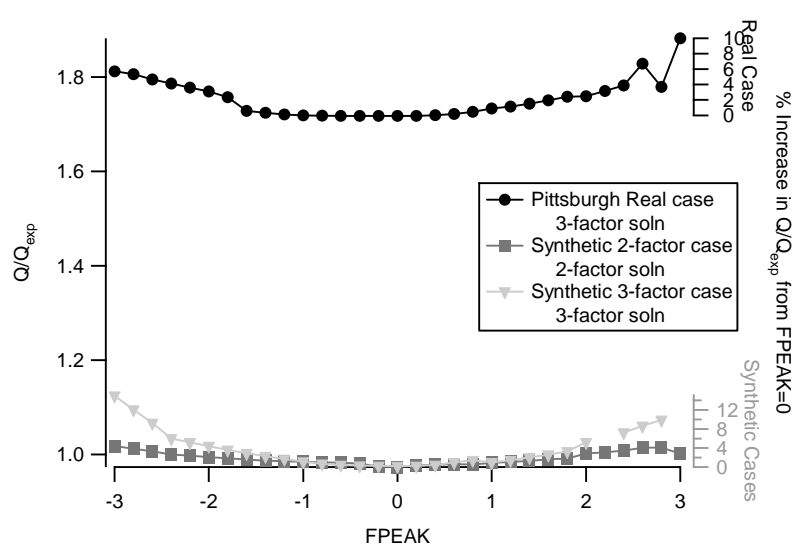

Fig. 9. $Q / Q_{\exp }$ vs. FPEAK for the real Pittsburgh case with 3 factors, the 2-factor synthetic base case with 2 factors, and the 3 -factor synthetic base case with 3 factors.

is very similar to the OOA-2 time series from the threefactor solution $\quad\left(\mathrm{UC}_{3-\text { factor } Q / Q_{\text {exp }}, 3-\text { factor } \mathrm{OOA}-2}=0.70\right.$, $\mathrm{UC}_{4-\text { factor } Q / Q_{\text {exp }}, 4-\text { factor OOA-2 }}^{\mathrm{TS}}=0.75$, and $\mathrm{UC}_{5-\text { factor } Q / Q_{\text {exp }}, 5 \text {-factor OOA-2 }}^{\mathrm{TS}}=0.78$ ). $\quad$ Adding more factors results in only minor changes in the TS of $Q / Q_{\exp }$ contributions and residual, implying that the same data variation fit by the lower order solution is being refit with more factors. In fact, the decrease in the TS of $Q / Q_{\exp }$ (improvements in the fit) in solutions with 3 to 6 factors do not occur during periods of high HOA or OOA-2, and only occasionally during periods of high OOA-1 (Fig. S10, see http://www.atmos-chem-phys.net/9/2891/ 2009/acp-9-2891-2009-supplement.pdf). The highest spike in the residual TS, a short-lived event on the evening of 14 September 2002, is likely due to a specific HOA plume (e.g., a specific combustion source) whose spectrum is similar to but has some differences from the main HOA factor during the study and shows variation in $m / z$ peaks with higher contribution to HOA than OOA-2. SVD of the unscaled residual matrix after fitting 3 factors (Fig. 3d) shows that with even 12 more factors, less than $95 \%$ of the remaining variance can be explained (150 factors would be needed to explain 95\% of the variance in the matrix of scaled residuals that was not downweighted for weak $m / z$ 's or those proportionally related to $m / z 44$ ). The residual at specific $m / z$ 's during periods of high OOA-2 and high $Q / Q_{\text {exp }}$ changes for many significant OOA-2 $\mathrm{m} / \mathrm{z}$ 's in modest amounts, fairly continuously, over periods of $10-20 \mathrm{~min}$. This is likely caused by variations in the true OOA-2 spectrum (which could occur, e.g., during condensation or evaporation of SVOCs) that cannot be represented by the constant-MS factor, nor are constant enough to become their own factor. These behaviors imply that three factors have explained as much of the data as is possible with a bilinear model with constant spectra.

\subsubsection{Rotations}

The three factor solution, which is the most interpretable as discussed above, is tested for its rotational ambiguity. The FPEAK range required for the $Q / Q_{\text {exp }}=10 \%$ criterion in the real data is -4.2 to +4.4 . Solutions with FPEAKs between -1.6 and +1.0 give an increase of $1 \%$ over $Q / Q_{\exp }$ at FPEAK=0 (Fig. 9). MS and TS spanning this range of solutions are shown in Fig. 10. Note that changing FPEAK changes both the MS and TS simultaneously. Overall, the effect of positive FPEAK is to create more near-zero values in the MS and decrease the number of near-zero values in the TS. The effect of negative FPEAK is to create more near-zero values in the TS and decrease the number of nearzero values in the MS. Note for example that the TS of the FPEAK $=-1.6$ solution have periods of zeros that do not correlate with any interpretable events, likely indicating that this solution represents rotation beyond the range that gives useful insight for this dataset. Changes in TS occur more in some periods than others. Mass concentration of all factors remain fairly constant at all FPEAKs during periods in which at least one factor has a mass concentration near zero, but periods in which all factors have non-zero mass concentrations show more variation as FPEAK is changed. This is most dramatic for the OOA-2 events on 13 and 14 September 2002, in which negative FPEAKs give more mass to the OOA-2 factor and less mass to the OOA-1 factor compared to solutions with FPEAK $\geq 0$. These differences represent one way of characterizing the uncertainty of the PMF solutions, since the $Q / Q_{\exp }$ values change little between them and all the TS and MS appear physically plausible. The solutions from multiple FPEAKS (Fig. 10) show a greater range in MS than the bootstrapping 1- $\sigma$ variation bars, while the TS show a similar range to the bootstrapping $1-\sigma$ variation bars (Fig. S7, see http://www.atmos-chem-phys.net/9/2891/2009/ acp-9-2891-2009-supplement.pdf).

The MS change with FPEAK is most dramatic in the OOA-2 MS, while the OOA-1 MS changes very little with FPEAK. This is not surprising since OOA-2 accounts for a low fraction of the total signal and thus its spectrum can change more without causing large increases in the residuals. At large negative values of FPEAK, the OOA-2 factor strongly resembles the HOA factor $\left(\mathrm{UC}_{\mathrm{OOA}-2, \mathrm{HOA}}^{\mathrm{MS}}\right.$ at FPAK $\left.=-1.6=0.98\right)$. The ratio of $m / z 43$ to $m / z 44$ in OOA-2 decreases from 2.1 to 1.1 and 0.55 as FPEAK increases from -1.6 to 0 and +1.0 , respectively. A sharp decrease in the fraction of signal attributed to $m / z 55$ relative to a small decrease in $m / z 57$ (ratios of $0.88,0.50$, and 0 at FPEAKs $-1.6,0$, and +1.0 , respectively) gives $m / z 57$ an unusually high fraction of the signal in OOA-2 at large positive FPEAKs. Positive FPEAK values also reduce the fraction of $m / z 44$ (mainly $\mathrm{CO}_{2}^{+}$) attributed to the HOA MS.

Diagnostic graphs of the correlations between each of the three factors from the real case, and how these correlations change with FPEAK, are shown in Fig. 11a 

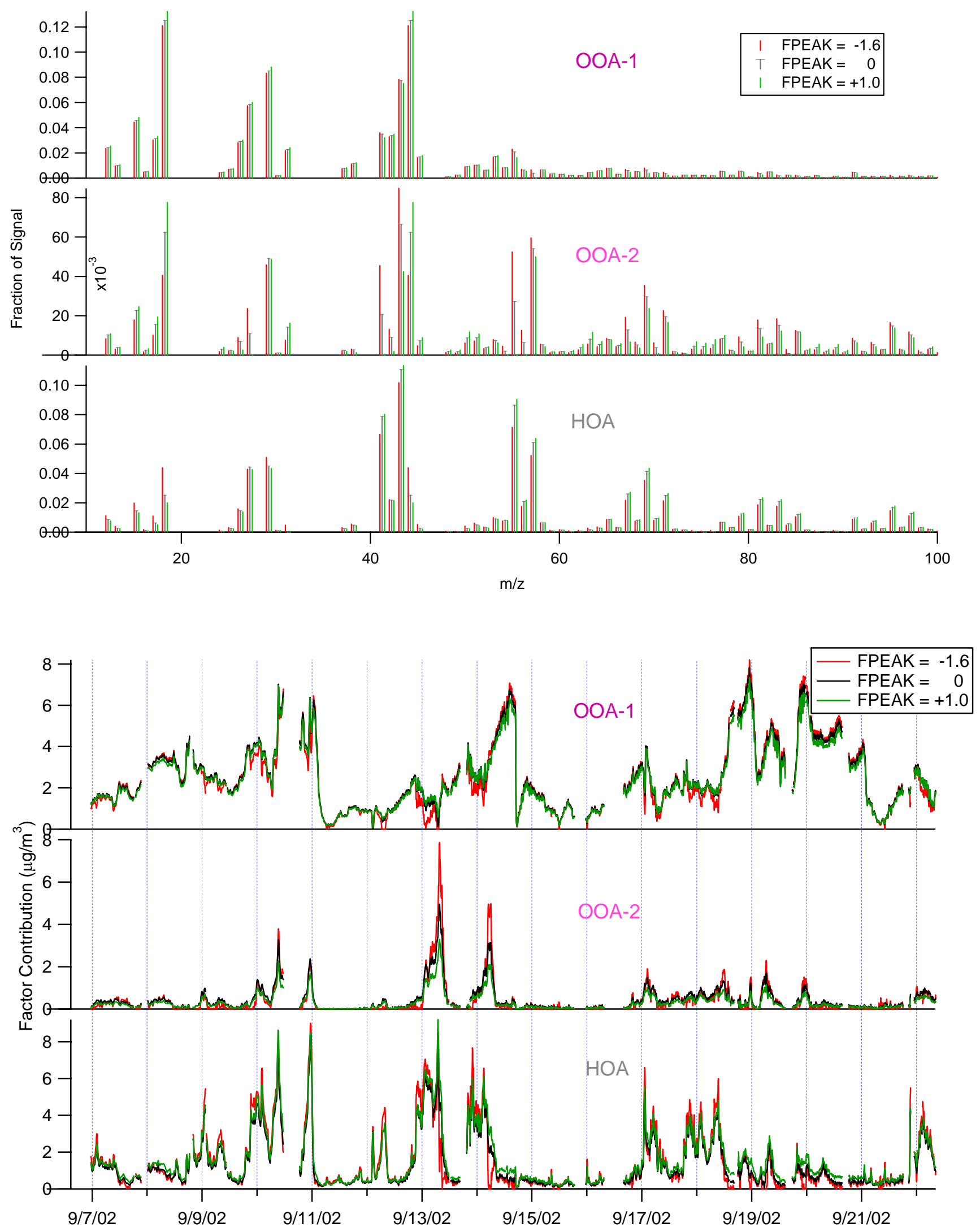

Fig. 10. 3-factor solutions of the real Pittsburgh case for selected FPEAK values. 

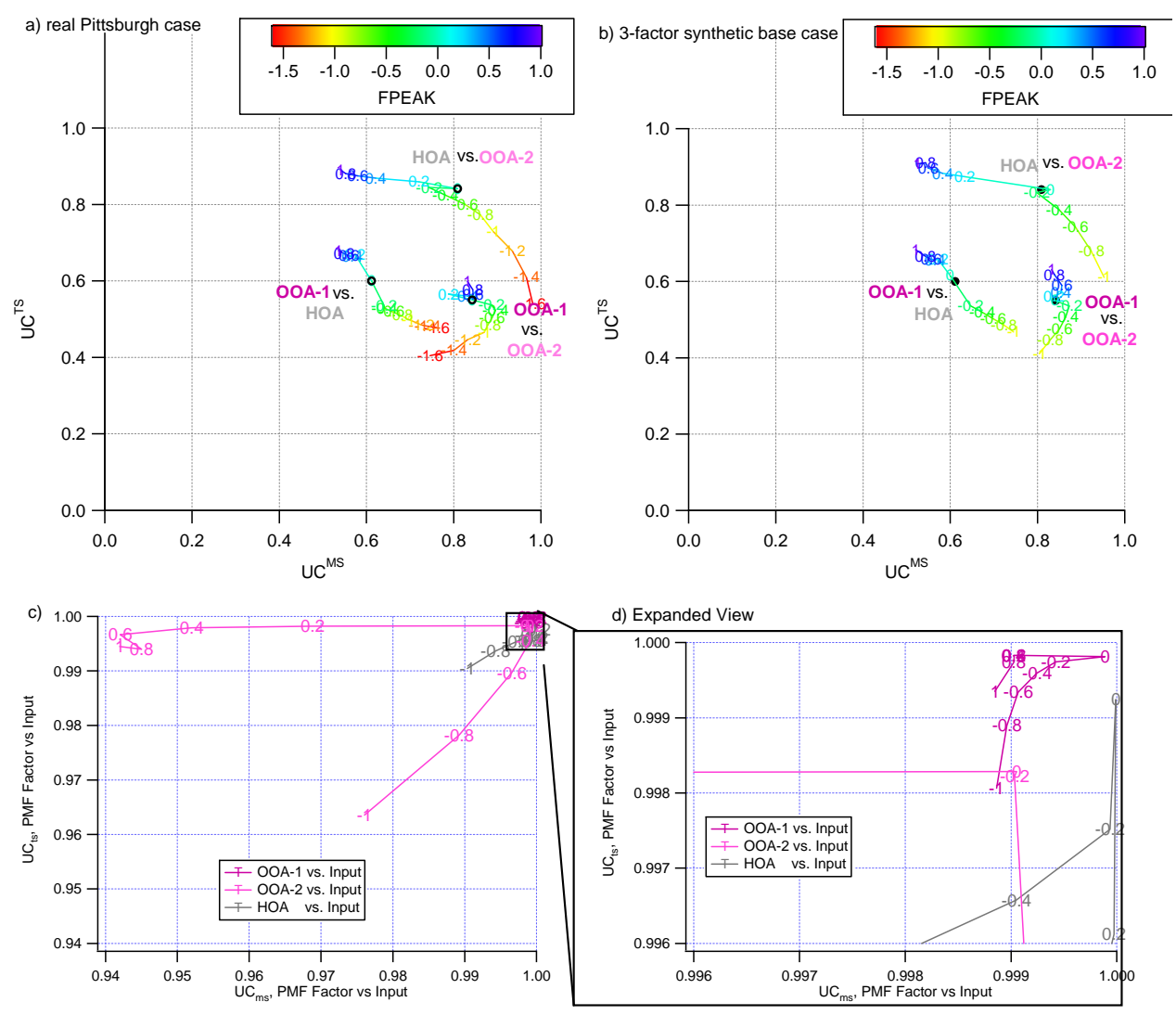

Fig. 11. Correlations for PMF factors to each other as they change with FPEAK for (a) the real Pittsburgh case and (b) the three-factor synthetic base case. Traces are colored by FPEAK and numbers denote the FPEAK of each solution. Black dots in (b) indicate the correlation of the factors in the input. (c) Correlation of the PMF factors to the input factors for the three-factor synthetic case. (d) Expansion of (c).

(Fig. S11a, see http://www.atmos-chem-phys.net/9/2891/ 2009/acp-9-2891-2009-supplement.pdf). The OOA-2 factor is highly correlated in MS with both the HOA and $\mathrm{OOA}-1$ factors at $\mathrm{FPEAK}=0\left(\mathrm{UC}_{\mathrm{OOA}-2, \mathrm{HOA}}^{\mathrm{MS}}=0.81\right.$, $\mathrm{UC}_{\mathrm{OOA}-2, \mathrm{OOA}-1}^{\mathrm{MS}}=0.84$, respectively), but has a more correlated time series with HOA than with OOA-1 $\left(\mathrm{UC}_{\mathrm{OOA}-2, \mathrm{HOA}}^{\mathrm{TS}}=0.84, \mathrm{UC}_{\mathrm{OOA}-2, \mathrm{OOA}-1}^{\mathrm{TS}}=0.55\right)$. As expected, the behavior of positive values of FPEAK is to mix the time series, making them more correlated and the mass spectra less correlated, moving these solutions toward the upper left of the graph. Negative values of FPEAK do the opposite. Note that this type of graph is very sensitive to small changes in the solution TS and MS. We find no evidence that solutions with FPEAKs away from zero are preferable.

\subsection{Synthetic AMS data}

It is clear from the analysis of this ambient dataset that there is significant ambiguity in the "correct" choice of the number of factors and rotations of the solutions. In this section we seek to evaluate the behavior of PMF2 and the appearance of its solutions for AMS synthetic datasets for which the true solution is known and for which well-specified and realistic noise is the only additional content in the data matrix. This type of analysis will help in the interpretation of the solutions from real cases.

\subsubsection{Solutions of synthetic data base cases}

\section{Solutions as a function of number of factors}

As AMS organic datasets have a specific structure with strong interrelation across $\mathrm{m} / \mathrm{z}$ 's and auto- and crosscorrelation time scales of the order of hours to days for most components and datasets, it is of interest to examine what PMF2 reports when too few or too many factors are requested by the user when the correct number of factors is known.

$Q / Q_{\exp }$-values and maximum value of RotMat for the two- (and 3-) factor synthetic base case for solutions up to 7 factors are shown in Fig. $3 b$ (3c) for FPEAK=0. $Q / Q_{\exp }$ is $\gg 1$ for the one-factor solution and is $\approx 1$ for all solutions of 2 (3) or more factors. This is the expected behavior; one factor should not fully explain the data and a high residual is reasonable. With the addition of a second (third) factor, most of the dataset is explained and the residual is on the order of the noise. As the simulated noise has a large 
number of degrees of freedom, solutions with more than two (three) factors are not able to explain more of the data and $Q / Q_{\text {exp }}$ is approximately constant. Max(RotMat) does not show a clear trend with number of factors. The maximum is at three (two) factors and a local minimum occurs at six (four) factors. No criterion for choosing the correct number of factors from max(RotMat) can be determined from these cases.

Mass spectra and time series for the 2- to 5-factor solutions of the 2- and 3-factor synthetic base cases are shown in Figs. S12 and S13, see http://www.atmos-chem-phys. net/9/2891/2009/acp-9-2891-2009-supplement.pdf. Mass fractions of the 2- to 7-factor solutions of the 2- and 3 -factor synthetic base cases for $\mathrm{FPEAK}=0$ are shown in Figs. $4 \mathrm{~b}$ and $\mathrm{c}$. The correct number of factors (2 or 3 )

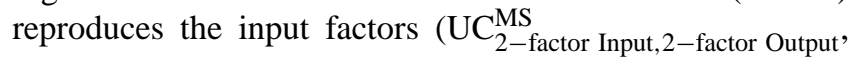

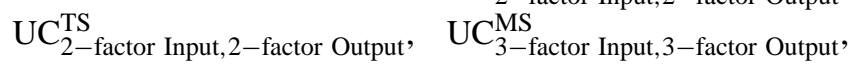
$\mathrm{UC}_{3 \text {-factor Input,3-factor Output }}^{\mathrm{TS}}>0.99$ ) very well. When more factors are calculated, factors highly similar to the input factors are retained and the additional factors have strong resemblance to one of these factors. For example, the 4-factor solution of the 3-factor base case has HOA and OOA-2 factors highly similar to the input for these

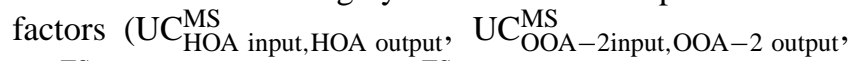
$\mathrm{UC}_{\mathrm{HOA}}^{\mathrm{TS}}$ input, $\mathrm{HOA}$ output, $\left.\quad \mathrm{UC}_{\mathrm{OOA}-2 \text { input,OOA-2 output }}^{\mathrm{TS}}>0.99\right)$ but two OOA-1 factors appear ( $\mathrm{UC}_{\mathrm{OOA}}^{\mathrm{MS}}$

$\mathrm{UC}_{\mathrm{OOA}-1 \text { input, OOA-1a Output }}^{\mathrm{MS}}>0.99$;

$\mathrm{UC}_{\mathrm{OOA}-1 \text { input,OOA-1 output }}^{\mathrm{TS}}>0.99$,

$\left.\mathrm{UC}_{\mathrm{OOA}-1 \text { input, } \mathrm{OOA}-1 \mathrm{a} \text { Output }}^{\mathrm{TS}}=0.97\right)$ with 42 and $20 \%$ of the fit mass, respectively. The OOA-1 factor has been "split" into two. This behavior continues with more factors in both base cases. Split factors have very similar MS and TS to each other and to the same factor in the $p-1$ factor solution with approximately equal splitting of the mass between the like factors.

The 3-factor solution of the 2-factor base case shows another interesting behavior (Fig. S12b, see http://www.atmos-chem-phys.net/9/2891/2009/ acp-9-2891-2009-supplement.pdf). One factor is very similar to the HOA input factor $\left(\mathrm{UC}_{\mathrm{HOA}}^{\mathrm{MS}}\right.$

$\mathrm{UC}_{\mathrm{HOA}}^{\mathrm{TS}}$ Input,3-factor HOA $\left.>0.99\right)$ and one factor very similar to the OOA input factor ( $\mathrm{UC}_{\mathrm{OOA}}^{\mathrm{MS}}$ Input,3-factor OOA, $\mathrm{UC}_{\mathrm{OOA}}^{\mathrm{TS}}$ Input,3-factor OOA $>0.99$ ). The third factor's spectrum includes high-signal peaks from both the HOA and OOA spectra. It is highly correlated with both the input HOA and OOA spectra ( $\mathrm{UC}_{\mathrm{HOA} \text { Input,3-factor Mixed }}^{\mathrm{MS}}=0.78$, $\mathrm{UC}_{\mathrm{OOA}}^{\mathrm{MS}}$ Input,3-factor Mixed $=0.91$, whereas the correlation between the input $\mathrm{HOA}$ and $\mathrm{OOA}$ spectra $\left(\mathrm{UC}_{\mathrm{HOA} \text { Input,OOA Input }}^{\mathrm{MS}}\right)$ is only 0.43$)$. This third factor lies $3.1^{\circ}$ out of the plane of the HOA and OOA spectra. A true linear combination would be in the HOA/OOA plane $\left(0^{\circ}\right)$; in two-factor synthetic cases without added Poisson and electronic noise, the third factor is a true linear combination of the HOA and OOA spectra and lies in the plane of the HOA and OOA factors. Thus it is the presence of the noise that allows the third factor to be slightly outside the 2component plane. This factor represents a "mix" of the true HOA and OOA spectra, especially because of the increased fraction of $m / z 44$ compared to the input HOA $(<1 \%$ in the HOA input, $7 \%$ in the mixed factor). We therefore choose to call it a "mixed" HOA/OOA factor. This "mixed" factor, however, has a time series that is similar to the HOA time series $\left(\mathrm{UC}_{\mathrm{HOA}}^{\mathrm{TS}}\right.$ Input, $3-$ factor Mixed $\left.=0.97\right)$ and it takes $11 \%$ of the total mass, taking more from HOA than OOA mass. Because we created a 2-factor input, we know that this is not a true factor. Nevertheless, the profile of this "mixed" factor is very similar $\left(\mathrm{UC}_{\text {Mixed Factor,Database Spectra }}^{\mathrm{MS}}>0.9\right)$ to multiple mass spectra from the AMS Spectral Database as shown in Fig. 6c (Fig. S4c, Table S2, see http://www.atmos-chem-phys.net/ 9/2891/2009/acp-9-2891-2009-supplement.pdf), including $\mathrm{SOA}$ from chamber reactions (e.g., $\beta$-caryophyllene $+\mathrm{O}_{3}$, $\alpha$-terpinene $+\mathrm{O}_{3}$ ), and particles from combustion of biomass or biomass components (e.g., ceanothus, juniper). In fact, this "mixed" spectrum has higher correlation with many of the SOA and BBOA spectra than the OOA-2 spectrum from the real Pittsburgh case (Fig. 6a). No mixed factors are observed in the 3-factor base case, indicating that the tendency of PMF to "mix" or "split" factors in its solutions (when too many factors are requested) is not easily predicted and can shift with relatively small changes in the input matrix (such as the addition of an OOA-2 input factor with $10 \%$ of the mass here).

\section{Uncertainty of the solutions of synthetic data}

In order to explore the possibility of multiple local minima in the solutions and the repeatability of the splitting behavior of the synthetic datasets, as well as to qualitatively assess variability in the factors, trials with 64 multiple starts were calculated for the 2-factor and 3-factor synthetic cases with solutions up to 6 factors. Similar to the real case, the range of $Q / Q_{\exp }$ values across the seeds was quite small, with the greatest difference in the 2- (3)-factor case of $2 \times 10^{-4}$ $\left(1 \times 10^{-6}\right) Q / Q_{\exp }$ units above the minimum. No local minima were identified in the 3 -factor synthetic cases. In the 2-factor synthetic cases, local minima are identified in solutions with 3 or more factors. The solutions fall into groups in which one factor represents the input OOA, one factor the input $\mathrm{HOA}$, and the other factors show various degrees of mixing of the HOA and OOA factors, as was described in Eqs. $(5,6)$. The three-factor solution of the 2-factor synthetic case shown in Fig. S12b is representative of the most common type of solution identified. Bootstrapping analysis of the synthetic cases with the correct number of factors results in 1- $\sigma$ variation bars of the same order or smaller than in the real case. 


\section{Rotations of the 3-factor synthetic base case solution}

In this section we examine the range of "rotatability" of the solutions. The FPEAK values required for the $Q / Q_{\exp }$ increase from its minimum by e.g. $10 \%$ in synthetic data can be quite large; FPEAK $= \pm 3.0$ for the 2-factor case gives an increase in $Q / Q_{\exp }$ of only about $4 \%$, but an FPEAK range of -1.0 to +1.0 in the 3 -factor case gives an increase in $Q / Q_{\text {exp }}$ of $1 \%$ (Fig. 9). MS and TS spanning this range of solutions are shown in Fig. S14, see http://www.atmos-chem-phys.net/ 9/2891/2009/acp-9-2891-2009-supplement.pdf. Changes in the MS and TS are similar to those in the real Pittsburgh case. In the TS, mass concentrations during periods in which all factors have non-zero mass concentration show more variation as FPEAK is changed and remain approximately constant in periods in which at least one factor has near-zero mass concentration. The MS change with FPEAK is most dramatic in the OOA-2 MS, while the HOA and OOA-1 MS change very little with FPEAK. The changes of the OOA-2 MS with FPEAK are similar to those of the real Pittsburgh case, with a strong resemblance to the HOA factor at negative FPEAK values $\left(\mathrm{UC}_{\mathrm{HOA}, \mathrm{OOA}-2 \text { at } \mathrm{MPEAK} \leq-1},>0.95\right)$ and change of its fraction of $m / z 44$ with increasing FPEAK values, from $6 \%$ at FPEAK 0 to $8 \%$ at FPEAK 1.0.

A graphical diagnostic of the correlations of each of the three factors versus each other and how they change with FPEAK is shown in Fig. 11b (Fig. S11b, see http://www.atmos-chem-phys.net/9/2891/2009/ acp-9-2891-2009-supplement.pdf). The input factors are reproduced best near 0 FPEAK values (Figs. $11 \mathrm{c}$, d, $\mathrm{S} 11 \mathrm{c}, \mathrm{d})$. The effect of FPEAK on the correlation of the factors is extremely similar to that in the real Pittsburgh case, with positive values of FPEAK making them more correlated and the mass spectra less correlated and negative values of FPEAK doing the opposite, making the time series less correlated and the mass spectra more correlated. The length of the segment between adjacent FPEAK solutions indicates the relative amount of change between the factors.

\section{Residuals in the 3-factor synthetic base case}

The $Q / Q_{\exp }$ contribution as a function of time for the 1-, 2-, and 3 -factor solutions of the 3 -factor base case are shown in Fig. 7c. The 1- and 2-factor solutions have distinct structure which indicates that all of the variation in the data has not been fit. In the three-factor solution, which reproduces the three input factors very well ( $\mathrm{UC}_{\text {Input,3-factor Output' }}^{\mathrm{MS}}$, $\mathrm{UC}_{\text {Input,3-factor Output }}^{\mathrm{TS}}>0.99$ for all three factors), the $Q / Q_{\text {exp }}$ contribution has no visible structure. SVD of the unscaled residual matrix (Fig. 3d) shows that even with 15 more factors, only about $75 \%$ of the remaining variance can be explained. These observations indicate that only random noise remains.

\subsubsection{Separation of correlated factors}

Another important question when analyzing PMF results is: how similar (correlated) can the factors be (in MS, TS, or both) and still be correctly retrieved by PMF? In one extreme case, two different sources that are completely correlated in time $\left(\mathrm{UC}^{\mathrm{TS}} \sim 1\right)$ cannot be separated by PMF or any other factorization method, as there is no information for their separation. Even if their MS are very different, only the sum of the two sources can be retrieved. Similarly, two sources with very highly correlated $\mathrm{MS}\left(\mathrm{UC}^{\mathrm{MS}} \sim 1\right)$ cannot be retrieved separately, irrespective of how different their time series are; again, only their sum can be retrieved. If the correlation between the input factors is plotted in a graph with $\mathrm{UC}^{\mathrm{MS}}$ as the $\mathrm{x}$-coordinate and $\mathrm{UC}^{\mathrm{TS}}$ as the $\mathrm{y}$-coordinate (as in Fig. 11a, b), the "irretrievable" regions include the edges of the plot near $\mathrm{UC}_{\text {Factor } k \text {,Factor } j}^{\mathrm{TS}}$ or $\mathrm{UC}_{\text {Factor } i \text {,Factor } j}^{\mathrm{MS}}=1$. It would be of interest to evaluate how far two factors have to be from those edges to be retrievable with some accuracy by PMF, and how the rotational uncertainty changes as the factors are closer or farther from those edges. Likely this "distance" from the edges will not be an absolute criterion, but will depend on the fraction of the mass accounted by each factor, i.e. a small factor may be harder to retrieve in this situation since its variance is smaller compared to noise and potential variations in the spectra of the larger components. This is a complex mathematical problem, complicated by the need to understand and maintain the number and placement of "nearzero" values in the factor MS and TS while changing the correlations between the input factors (Paatero, 2008a; Ulbrich et al., 2008). In the present work, only the retrieval of factors with a given correlation and varying fractions of the mass is explored.

\section{Separation of small factors: three-factor synthetic cases}

The correlations between the factors in the variations on the 3-factor synthetic base case (described above in Sect. 2.3) are shown in Fig. 12a (Fig. S15a, Table S3, see http://www.atmos-chem-phys.net/9/2891/2009/ acp-9-2891-2009-supplement.pdf). Replacing the OOA2 MS with one of three database spectra (BBOA, SOA, or fulvic acid (FA) MS) gives a broad range of correlations of the third factor with $\mathrm{HOA}\left(U C_{\mathrm{HOA}, \mathrm{BBOA}}^{\mathrm{MS}}=0.88\right.$, $\mathrm{UC}_{\mathrm{HOA}, \mathrm{OOA}-2}^{\mathrm{MS}}=0.81, \quad \mathrm{UC}_{\mathrm{HOA}, \mathrm{SOA}}^{\mathrm{MS}}=0.76, \quad \mathrm{UC}_{\mathrm{HOA}, \mathrm{FA}}^{\mathrm{MS}}=0.39$ ) and a narrower range of correlations between OOA1 and the third factor (from $\mathrm{UC}_{\mathrm{OOA}=1, \mathrm{BBOA}}^{\mathrm{MS}}=0.81$ to $\mathrm{UC}_{\mathrm{OOA}-1, \mathrm{FA}}^{\mathrm{MS}}=0.89$ ). We now consider how well PMF can retrieve these factors with average mass fractions between $0.7 \%$ and $11.4 \%$.

The ability to retrieve the small factor is assessed by correlation with the input factor (Figs. 12b, S15b). For mass fractions of $11.4 \%$, the small factor was retrieved well at FPEAK=0 with $\mathrm{UC}_{\text {Small Factor Input,Small Factor Output }}^{\mathrm{MS}}>0.99$, 

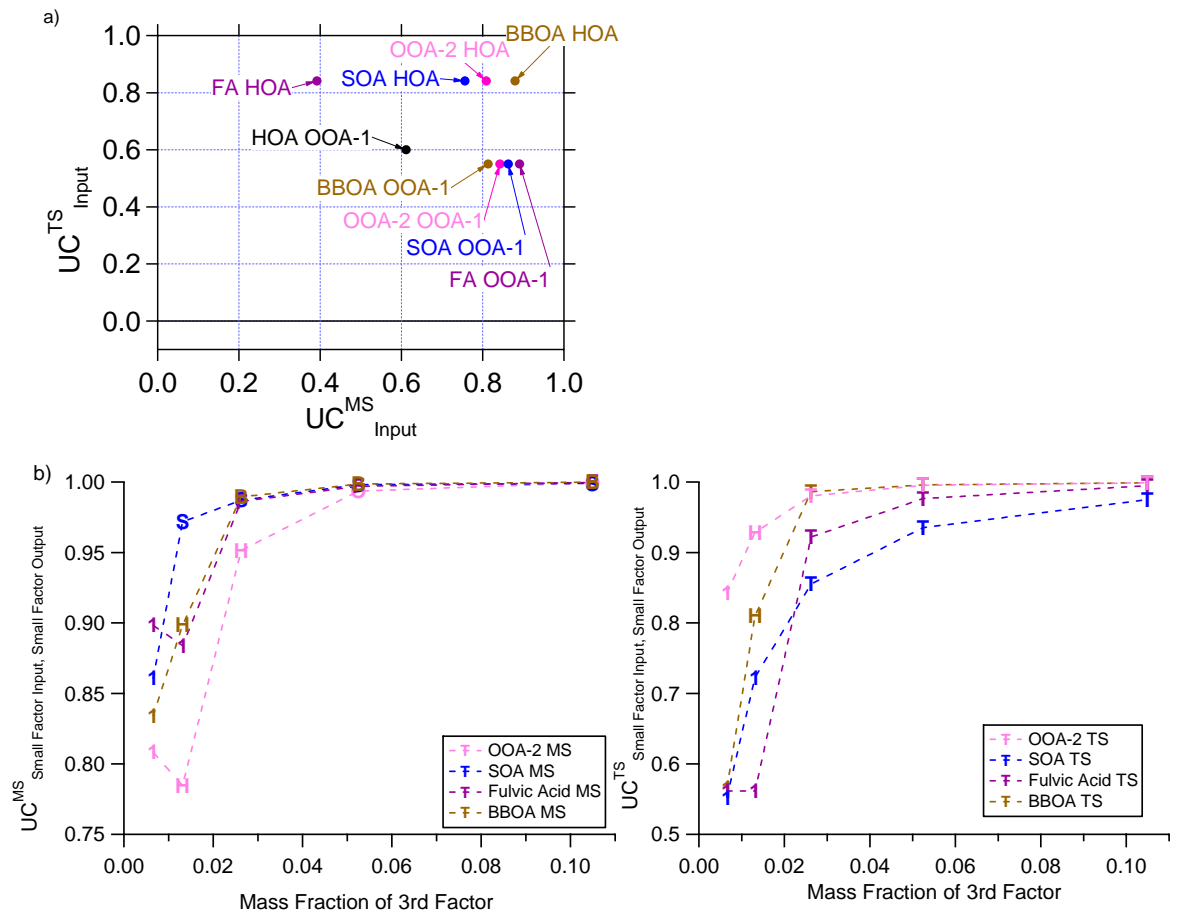

Fig. 12. (a) Correlations between 3 -factor real output and all synthetic input cases. (b) Retrieval correlations between PMF and input TS and MS versus mass fraction of different third factors in synthetic cases. Markers denote the resemblance of the factors to the input MS or TS. For the MS, O, S, F, and B refer to OOA-2, SOA, FA, and BBOA, respectively. For the TS, T refers to the input TS. For both cases, H and I refer to HOA and OOA-1, respectively.

$\mathrm{UC}_{\text {Small Factor Input, Small Factor Output }}^{\mathrm{TS}}>0.97$. As the average mass fraction of the small factor is decreased, the small factor is not retrieved as accurately in some cases. Both the MS and TS of the small factor can be retrieved with $\mathrm{UC}_{\mathrm{Small}}^{\mathrm{MS}}$ Factor Input,Small Factor Output $>0.97$ (except for the SOA case) and $\mathrm{UC}_{\text {Small Factor Input,Small Factor Output }}^{\mathrm{TS}}>0.99$ when the small factor has at least $5 \%$ of the average mass. As the average mass fraction of the small factor decreases, the third factor may have greater similarity to HOA or OOA1 in MS or TS than to the input factor. These behaviors have elements similar to the splitting behavior observed in the synthetic base cases when too many factors were chosen. Although the mass spectrum of the third factor input does not change as the mass is reduced, the ability of PMF to retrieve both the mass spectrum and time series decreases as the fraction of the mass decreases. Based on this case study, we conclude that in Q-AMS datasets with only Poisson ion noise and Gaussian electronic noise, factors with a mass fraction of at least $5 \%$ are likely to be retrievable with sufficient accuracy for reliable interpretation. This should be a lower limit for real cases in which the noise may have additional structure. However if the small factor has a very different time series from those of the main factors (e.g. if it is a spiky local source or has a distinctive MS) factors with smaller mass fractions may still be reliable retrieved (Huffman et al., 2009).

\section{Discussion}

In the ambient and synthetic data we compared various criteria for determining number of factors. The criterion for choosing the number of factors based on the behavior of $Q / Q_{\exp }$ vs. number of factors has the expected behavior for the synthetic datasets but does not lead to a strong conclusion for the real data case (Fig. 3). The $Q / Q_{\exp }$ of the real dataset has a steep decrease from 1 to 2 factors, but a steady decrease with more factors does not point to a particular choice for number of factors. Our choice of a three-factor solution for the real case is justified by tracer correlations, spectral comparisons and interpretation (e.g., $m / z 44$ as a surrogate for $\mathrm{O}: \mathrm{C}$ ratio), and residual analysis, and is a good physical explanation of the data. We conclude that a criterion based on a significant decrease in $Q / Q_{\exp }$ as the number of factors is increased is not sufficient to determine the correct number of factors in AMS datasets.

The criteria of the smallest maximum value of RotMat for the best solution proposed by Lee et al. (1999) is not met by any of the datasets. There is no theoretical reason to support the use of the $\max$ (Rotmat) criterion to determine the number of factors. The use of the $\max$ (Rotmat) criterion appears to be based in the assumption that true data should not have rotational ambiguity, and use of this criterion may favor the wrong number of factors if the data do have 
significant rotational ambiguity (Paatero, 2008b). In the synthetic datasets, $\max$ (RotMat) gives no indication about the correct number of factors. Since the criterion is not met for synthetic datasets, we draw no conclusion from this statistic for real datasets and do not recommend this as a basis for choosing the correct number of factors in AMS data. RotMat values are larger in the real case than for the synthetic case, suggesting additional rotatability in the real case.

The splitting and mixing behavior seen in the synthetic datasets when too many factors were requested presents a clear warning that when evaluating a real dataset, the researcher must be careful about overinterpreting solutions with multiple factors, even though it may be tempting to "identify" additional sources and give them physicalsounding names. The characterized splitting behavior in which each split factor has comparable fractions of the mass of the original factor may be specific to the PMF2 algorithm, as other algorithms such as MCA (Zhang et al., 2007a) tend to split a factor into a dominant factor (in terms of mass) and a small factor. In particular, care must be taken because the spurious factors obtained due to "splitting" or "mixing" behavior have realistic-looking mass spectra and time series and could easily be interpreted by the unsuspecting user as a real factor, though we know that in the synthetic cases these factors must be mathematical artifacts. In cases where mixing behavior occurs, non-existent factors could be retained. Thus, it is critical to use external tracers to confirm the interpretation. In the absence of these tracers, the lower order solution may be the best choice. In our ambient case, for example, factors 3-6 are mathematically good solutions. The fourth factor in the 4-factor solution of the real Pittsburgh dataset exhibits some of the behavior characterized by the splitting observed in the synthetic cases. The TS of this factor is very similar to the TS of the OOA-1 factor (Fig. S3b, see http://www.atmos-chem-phys.net/9/2891/ 2009/acp-9-2891-2009-supplement.pdf) and these two factors share approximately equal portions of the mass (Fig. 4a). The MS correlates well with many types of OA measured by the AMS (Fig. 6b). While this factor may reflect true variability in OOA-1, we do not have an independent tracer to support this interpretation and prefer the 3 -factor solution as the safest choice to avoid overinterpretation.

A key concern in having ambiguity in number of factors is whether the mass fraction of total OOA and HOA (and other major components such as BBOA) determined from a given PMF analysis depends on the number of factors that is used. The mass fraction of total HOA and OOA varies by approximately $\pm 10 \%$ in the real case and in the three-factor synthetic case and could be over- or underestimated depending on the choice of number of factors (Fig. 4). This determination is more complex in the two-factor synthetic case and depends strongly on whether the "mixed" factor is attributed to HOA or OOA, or to a new type of source. For solutions with more than 2 factors, both total HOA and total OOA could be underestimated while the mixed factor spuriously accounts for $9-26 \%$ of the mass. In the real case, the 2-factor solution slightly underestimates OOA. This behavior is counter to that seen by Lanz et al. (2007), where they observed that a 2 -factor solution significantly overestimated OOA in Zurich in the summer. Nemitz et al. (2008) found that the 2-factor solution significantly underestimated OOA by $17 \%$ in their case. Thus the tendency for a 2 -factor solution to over- or underestimate the OOA/HOA ratio is most likely dependent on the structure of a particular AMS dataset and no general trend is apparent.

In the ambient and synthetic cases we explored the use of FPEAK to explore rotations of the solutions. A $\Delta Q / Q_{\exp }$ over the minimum $Q / Q_{\exp }$ of $\sim 1 \%$ (rather than $10 \%$, P. K. Hopke, personal communication, 2007) seems to give a more appropriate range of FPEAKs for this Q-AMS dataset. Positive values of FPEAK mix the TS, making them more correlated and the MS less correlated, while negative values of FPEAK mix the MS, making them more correlated and the TS less correlated (Fig. 11). Choice of a particular FPEAK solution is complex. Mathematically, values of zero in the true factors (in MS or TS) help to constrain the rotation, but they must be known a priori to justify a particular FPEAK solution (Paatero et al., 2002, 2005). We have no such a priori information in the Pittsburgh case to constrain any values in the TS or MS to zero, and so have no mathematical way to choose a particular value of FPEAK. We have followed the guidance of Paatero et al. (2002) and present a range of solutions for our dataset to describe the degree of rotational ambiguity (Fig. 10).

Is it possible, then, to support the choice of any particular rotation? Paatero et al. (2005) suggest use of a graphical method for choosing a rotation such that the source contribution factors (TS) show weak statistical independence near the $\mathrm{x}$ - and $\mathrm{y}$-axes when contributions for pairs of factors are plotted in scatter plots. In AMS data, this usually requires lesscorrelated TS, i.e., negative FPEAKs. Based on our interpretation of the factors as primary OA, fresher SOA, and aged SOA, the concentrations of the factors may not be independent but may be linked by increases and decreases in regional dispersion and photochemistry, and such a rotation may not be warranted. FPEAKs from -1.2 to -1.6 give third factors (OOA-2 in solutions with FPEAKs $>-1.2$ ) that exhibit some of the behaviors of splitting (they are similar to HOA, i.e., too close to the right edge of Fig. 11a), but this may not be sufficient for rejecting them. The solutions from these FPEAKs create zeros in the TS that do not correspond to interpretable events (Fig. 10), and this may be sufficient qualitative justification for rejecting these solutions. No behaviors are observed in the solutions at large positive FPEAKs to support exclusion of these solutions.

A possible way to choose a rotation would be to maximize the correlation of the factor TS with external tracers. Though this has no mathematical basis, it could be justified when the researcher is confident of his/her interpretation of the factors. Note, however, that the interdependence 

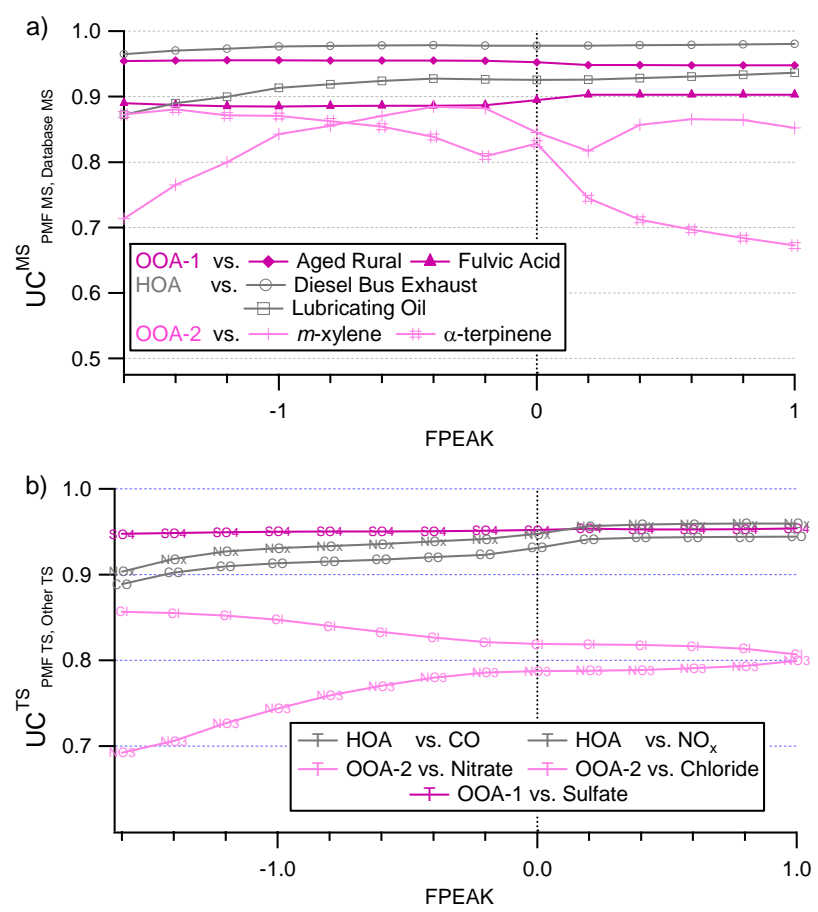

Fig. 13. Correlation versus FPEAK between PMF factor (a) MS and selected reference MS, and (b) TS and tracer TS.

of MS and TS during rotations strongly suggests that the change in MS with FPEAK also be considered. Figure 13 (Fig. S16, see http://www.atmos-chem-phys.net/ 9/2891/2009/acp-9-2891-2009-supplement.pdf) shows the correlation between each factor MS and TS with selected reference spectra and tracer species, respectively, versus FPEAK. While correlations with TS could support the choice of a positive FPEAK, correlations with the MS suggest that extreme FPEAKs distort the MS and FPEAKs closer to 0 appear more reasonable. Though this is not a very strong criterion for this dataset, we believe that the FPEAK=0 solution is the best representation of the retrievable factors for this case.

Separation of highly-correlated factors is a potential limitation of this technique with Q-AMS data. HR-ToF-AMS datasets contain more chemical information at each nominal $\mathrm{m} / \mathrm{z}$ with both oxygenated and non-oxygenated ions (e.g., $\mathrm{C}_{2} \mathrm{H}_{3} \mathrm{O}^{+}$and $\mathrm{C}_{3} \mathrm{H}_{7}^{+}$at $\mathrm{m} / z 43$ ) that will reduce the $\mathrm{UC}^{\mathrm{MS}}$ between true high-resolution components, increasing the retrievability of factors in those datasets (Aiken et al., 2009). Use of diagnostic plots such as those in Fig. 11 in Q-AMS and HR-ToF-AMS factorization is encouraged. We feel that great care must be taken when interpreting solutions in which output factors have MS and/or TS with UC $>0.9$, especially if they exhibit some characteristics of splitting or mixing behavior.
Studies with 3-factor synthetic cases demonstrate that factors with a small average mass fraction may not be accurately retrieved. Factors with at least 5\% of the mass were retrieved well in all cases studied. Factors with smaller mass fractions were often poorly retrieved, with their mass spectra not found and instead a 3rd component appeared due to behavior similar to "splitting" or "mixing" of the 2 dominant factors (Fig. 12). The inability to retrieve factors with a smaller fraction of the mass is a likely limitation of this technique with Q-AMS data.

It is important to note that we do not assign the factors of the AMS data to specific sources. For example, the calculated HOA spectrum is likely a linear combination of the HOA sources sampled across the study (encompassing both the range of MS of the sources and their relative mass fractions). For example, separating factors for diesel and gasoline vehicle emissions is very challenging in this analysis because the MS as measured in the AMS are extremely similar and a single HOA MS can represent both sources (and others with similar unit-resolution MS, Mohr et al., 2008). Therefore reported HOAs may vary between studies depending on the specific mix of sources measured during each study. Similarly, the types of OOAs reported in each study relate to the distribution of precursors and photochemical ages that happen to be sampled in that particular study. The MS of the OOA-1 and OOA-2 factors are likely interpolants of the key variations in sources and/or age that cause spectral variation in a particular study. Therefore the OOA-1's and OOA2 's reported in different studies should not be expected to be identical, reflecting differences in meteorology, transport time, and the mix of sources and precursors. Even for studies at the same location during different periods, these changes could lead to variations in the factor spectra.

The residual in the real dataset has considerable structure that changes very little with the addition of more factors, in stark contrast to the residual of the synthetic datasets, where the residual reflects only the noise added to the dataset when enough factors are chosen (Figs. 7, S8). Similar results are reported in other component analyses of AMS data (Zhang et al., 2005a; Lanz et al., 2007), so none of these studies is fitting all of the real structure in the dataset. This distinct structure in $Q / Q_{\exp }$ in the real dataset may imply that, though three factors have explained as much of the data as is possible with a bilinear model, something is changing during these periods of high residual and rotatability of the factors (Fig. 10). We hypothesize that aerosol partitioning or processing results in continuously, non-linearly varying spectra that cannot be fit well with the bilinear model. Evaporation and condensation of the semi-volatile OOA-2 component of the organic aerosol may lead to slight changes in composition that cannot be fit well with a constant mass spectrum. These changes in spectra, especially when fresh SOA/OOA is important in a dataset, may be a key limitation of the retrievability of the components in Q-AMS spectra. This should be a topic of further research. 


\section{Conclusions}

An organic mass spectral dataset from Pittsburgh in 2002 was analyzed by PMF. The behavior of PMF solutions with AMS data was characterized using several 2- and 3-factor synthetic datasets with realistic noise. Three factors are identified from the Pittsburgh data. Two factors (HOA and OOA-1) are similar to the factors identified by Zhang et al. (2005a). A third factor was identified as OOA-2, a semi-volatile, lessoxidized OOA whose time series correlates strongly with those of ammonium nitrate and ammonium chloride. The solutions are repeatable at different random starts and bootstrapping analysis supports the robustness of the solution. Researchers are urged to make these analyses, as well as to make other appropriate comparisons, such as between the results from robust and non-robust modeling. There is no clear support for justifying solutions with more than three factors for this dataset. Note that this does not mean that there are only three sources, but rather that sources with very similar spectra (e.g., gasoline and diesel engine emissions) cannot be separated in this analysis with UMR data. Any sources that can be approximated by linear combinations of the PMF factors are likely partitioning among the retrieved factors and are not retrievable separately. Solutions with more than 3 factors appear to "split" the existing factors, a characteristic observed in synthetic datasets when more factors were calculated than existed in the input. Additional factors make minor changes in the residual of the Pittsburgh case, but appear to primarily refit the same variation in the data. We hypothesize that the structure in the residual reflects continuous, nonlinear changes in the OOA-2 spectra as the aerosols partition or age, which cannot be fit by the bilinear model.

While the determination of a "best" solution is subjective and challenging in a real dataset, measures can be taken to make this process more quantitative. Correct specification of estimated error values, $\sigma_{i j}$ for the dataset help prevent nonsensical factors (e.g., MS with one dominant fragment, TS that oscillate between zero and several $\mu \mathrm{g} / \mathrm{m}^{3}$ over short time intervals). Real and synthetic data indicate that plots of $Q / Q_{\text {exp }}$ vs. number of factors give a good indication of the minimum number of factors, but are not a sufficient criterion for choosing the best number of factors. Multiple random seeds should be tested to explore the possibility of local minima in the $Q$ space, and bootstrapping should be used to evaluate the statistical uncertainty of the candidate solutions. Max(RotMat) does not give any useful indication of the best number of factors. Interpretation of the PMF solutions should start with the factor profiles (here, mass spectra). We have created a public, web-accessible database of AMS spectra which can be compared to spectra from PMF results to help identify and name the factors. Spectral similarity is not sufficient for naming factors, as "mixed" or "split" factors can have high similarity with many spectra in the database. Thus, correlations of time series with species not included in the PMF analysis are critical to give additional evidentiary

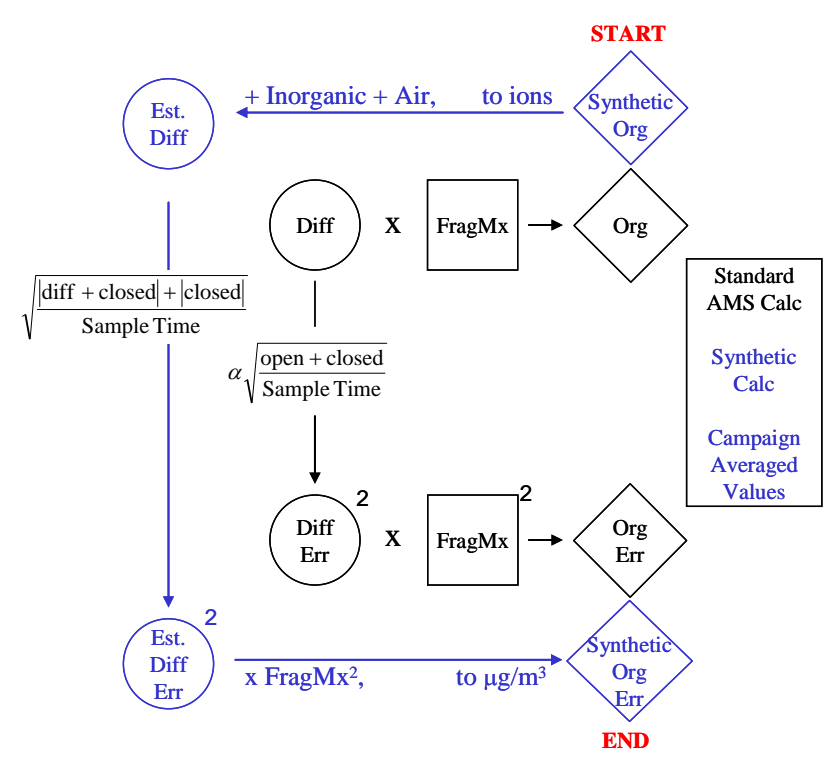

Fig. A1. Schematic diagram for calculation of error matrices for real (black path) and synthetic (blue path) AMS data.

support to a selected solution and interpretation. Best identification is made from supporting evidence for both mass spectra and correlation with tracer time series. It is imperative that both mass spectra and time series for each factor be presented because they are interdependent. Use of diagnostic plots showing the correlation between the factors in each solution is encouraged. It is unlikely that components with 5\% or less of the mass are meaningful for Q-AMS data. Solutions with two factors may over- or underestimate the fraction of OOA, and this behavior appears to be dependent on the structure of the dataset. There is generally not a mathematical basis for choosing a particular rotation (using the parameter FPEAK), though correlation with external tracers and reference mass spectra may be used to narrow the set of plausible rotations. Presentation of solutions for several representative FPEAKs will allow readers to understand the rotational behavior and variability of the factors. A $\Delta Q / Q_{\exp }$ over the minimum $Q / Q_{\exp }$ of $\sim 1 \%$ seems to give appropriate range of FPEAKs for Q-AMS datasets.

\section{Appendix A}

\section{Calculation of error values for synthetic datasets}

The calculation of error values for real and synthetic data is described schematically in Fig. A1. In real datasets, the error, $\sigma_{\text {diff }}$, for the total difference signal (open beam - closed beam) at each point is estimated by

$\sigma_{\text {diff }}=\alpha \sqrt{\frac{I_{o}+I_{c}}{t_{s}}}$ 


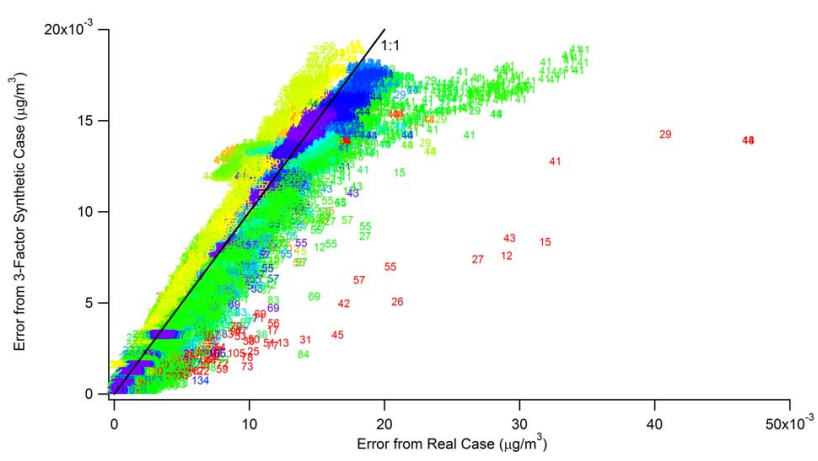

Fig. A2. Comparison of errors calculated for the Pittsburgh dataset (y-axis) and the synthetic two-factor dataset (x-axis). Markers are labeled by their $\mathrm{m} / \mathrm{z}$ and colored by time during the campaign (beginning is red, end is blue). The black line is a 1:1 line. Outlying red points are from the first sample (row of the matrix), made over less than the standard 5-min averaging time, decreasing the error from these points when using the longer campaign-averaged sample time. The large band of green outlying points is mainly from $m / z 41$, which had much higher than average background levels in the instrument during two events during the campaign.

where $\alpha$ is a factor of 1.2 applied to account for the random variation of the areas of single-ion signals, $I_{o}$ and $I_{c}$ represent the signal, in ion $\mathrm{Hz}$, of the open and closed beams, respectively, and $t_{s}$ is the time, in seconds, spent sampling each $\mathrm{m} / z$ (Allan et al., 2003). The error for a particular species (e.g., organics), $\sigma_{\text {species }}$, is calculated by propagating the application of a "fragmentation matrix" (Allan et al., 2004) to the total difference error $\sigma_{\text {diff, }}$ such that

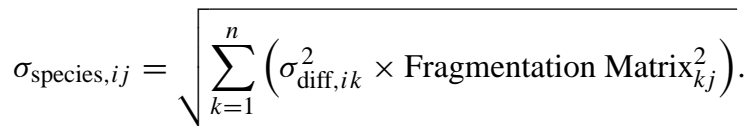

Note that in the synthetic case, neither the open beam nor closed beam values are known, so $\sigma_{\text {diff }}$ and $\sigma_{\text {species }}$ cannot be calculated directly. We therefore proceed through the following steps to estimate errors for synthetic data. The synthetic organics matrix, $\mathbf{X}_{\text {input }}$, is converted from $\mu \mathrm{g} / \mathrm{m}^{3}$ to $\mathrm{Hz}$ using the campaign-averaged conversion factor from the real Pittsburgh dataset. The matrices of inorganic species and air (in $\mathrm{Hz}$ ) are added to the organics matrix to give a total estimated difference matrix. The calculation of the $\sigma_{\text {diff }}$ matrix (Eq. A1) requires an estimated closed beam signal matrix, the estimated open beam signal, and the sample time per $m / z$. The closed signal is estimated as the campaign-averaged closed mass spectrum. The open signal is estimated as the estimated total difference matrix (representing open - closed) plus the campaign-averaged closed mass spectrum. The sample time per $\mathrm{m} / \mathrm{z}$ is estimated as the campaign-averaged sample time. Calculation of $\sigma_{\text {diff }}$ for the synthetic case uses $\alpha=1.2$. The calculation of the $\sigma_{\text {organic }}$ matrix (Eq. A2) uses the organics fragmentation matrix from the Pittsburgh dataset. The $\sigma_{\text {organic }}$ matrix is then converted from $\mathrm{Hz}$ back to $\mu \mathrm{g} / \mathrm{m}^{3}$ using the inverse of the campaignaveraged conversion factor used above. Comparison of the magnitude of the errors of the real dataset and the synthetic dataset is shown in Fig. A2, indicating that this procedure results in noise estimates very similar to those from the real dataset.

Acknowledgements. We are grateful to M. Hannigan, J. Milford, G. Brinkman, P. K. Hopke, P. Paatero, V. Lanz, A. Prevot, C. Hueglin, and the broader AMS community for helpful discussions; to P. Paatero for the mathematical description of split factors; to D. Sueper for support on the development of the PMF Evaluation Tool. This research was supported by grants EPA STAR RD-83216101-0, NSF ATM-0449815, NASA NNG04GA67G, and DOE DE- FG02-08ER64627, NOAA NA08OAR4310565, and by NASA graduate fellowship NNG05GQ50H to I. Ulbrich. This paper has not been reviewed by any of the funding agencies and thus no endorsement should be inferred.

Edited by: U. Pöschl

\section{References}

Aiken, A. C., Decarlo, P. F., Kroll, J. H., Worsnop, D. R., Huffman, J. A., Docherty, K. S., Ulbrich, I. M., Mohr, C., Kimmel, J. R., Sueper, D., Sun, Y., Zhang, Q., Trimborn, A., Northway, M., Ziemann, P. J., Canagaratna, M. R., Onasch, T. B., Alfarra, M. R., Prevot, A. S. H., Dommen, J., Duplissy, J., Metzger, A., Baltensperger, U., and Jimenez, J. L.: O/C and OM/OC ratios of primary, secondary, and ambient organic aerosols with highresolution time-of-flight aerosol mass spectrometry, Environ. Sci. Technol., 42, 4478-4485, doi:10.1021/es703009q, 2008.

Aiken, A. C., Salcedo, D., Cubison, M. J., Huffman, J. A., DeCarlo, P. F., Ulbrich, I. M., Docherty, K. S., Sueper, D., Kimmel, J. R., Worsnop, D. R., Trimborn, A., Northway, M., Stone, E. A., Schauer, J. J., Volkamer, R., Fortner, E., de Foy, B., Wang, J., Laskin, A., Shutthanandan, V., Zheng, J., Zhang, R., Gaffney, J., Marley, N. A., Paredes-Miranda, G., Arnott, W. P., Molina, L. T., Sosa, G., and Jimenez, J. L.: Mexico City aerosol analysis during MILAGRO using high resolution aerosol mass spectrometry at the urban supersite (T0) - Part 1: Fine particle composition and organic source apportionment, Atmos. Chem. Phys. Discuss., 9, 8377-8427, 2009, http://www.atmos-chem-phys-discuss.net/9/8377/2009/.

Alfarra, M. R.: Insights into Atmospheric Organic Aerosols Using an Aerosol Mass Spectrometer, Thesis, University of Manchester, UK, 2004.

Alfarra, M. R., Coe, H., Allan, J. D., Bower, K. N., Boudries, H., Canagaratna, M. R., Jimenez, J. L., Jayne, J. T., Garforth, A. A., Li, S. M., and Worsnop, D. R.: Characterization of urban and rural organic particulate in the lower Fraser valley using two aerodyne aerosol mass spectrometers, Atmos. Environ., 38, 57455758, doi:10.1016/j.atmosenv.2004.01.054, 2004.

Alfarra, M. R., Paulsen, D., Gysel, M., Garforth, A. A., Dommen, J., Prévôt, A. S. H., Worsnop, D. R., Baltensperger, U., and Coe, H.: A mass spectrometric study of secondary organic aerosols 
formed from the photooxidation of anthropogenic and biogenic precursors in a reaction chamber, Atmos. Chem. Phys., 6, 52795293, 2006, http://www.atmos-chem-phys.net/6/5279/2006/.

Alfarra, M. R., Prévôt, A. S. H., Szidat, S., Sandradewi, J., Weimer, S., Lanz, V. A., Schreiber, D., Mohr, M., and Baltensperger, U.: Identification of the mass spectral signature of organic aerosols from wood burning emissions, Environ. Sci. Technol., 41, 57705777, doi:10.1021/es062289b, 2007.

Allan, J. D., Jimenez, J. L., Williams, P. I., Alfarra, M. R., Bower, K. N., Jayne, J. T., Coe, H., and Worsnop, D. R.: Quantitative sampling using an Aerodyne aerosol mass spectrometer -1 . Techniques of data interpretation and error analysis, J. Geophys. Res. Atmos., 108, 4090, doi:10.1029/2002JD002358, 2003.

Allan, J. D., Delia, A. E., Coe, H., Bower, K. N., Alfarra, M. R., Jimenez, J. L., Middlebrook, A. M., Drewnick, F., Onasch, T. B., Canagaratna, M. R., Jayne, J. T., and Worsnopf, D. R.: A generalised method for the extraction of chemically resolved mass spectra from aerodyne aerosol mass spectrometer data, J. Aerosol Sci., 35, 909-922, doi:10.1016/j.jaerosci.2004.02.007, 2004.

Bahreini, R., Keywood, M. D., Ng, N. L., Varutbangkul, V., Gao, S., Flagan, R. C., Seinfeld, J. H., Worsnop, D. R., and Jimenez, J. L.: Measurements of secondary organic aerosol from oxidation of cycloalkenes, terpenes, and m-xylene using an Aerodyne aerosol mass spectrometer, Environ. Sci. Technol., 39, 56745688, doi:10.1021/es048061a, 2005.

Brinkman, G., Vance, G., Hannigan, M. P., and Milford, J. B.: Use of synthetic data to evaluate positive matrix factorization as a source apportionment tool for $\mathrm{PM}_{2.5}$ exposure data, Environ. Sci. Technol., 40, 1892-1901, doi:10.1021/es051712y, 2006.

Cabada, J. C., Pandis, S. N., Subramanian, R., Robinson, A. L., Polidori, A., and Turpin, B.: Estimating the secondary organic aerosol contribution to $\mathrm{PM}_{2.5}$ using the EC tracer method, Aerosol Sci. Technol., 38, 140-155, doi:10.1080/02786820390229084, 2004.

Canagaratna, M. R., Jayne, J. T., Ghertner, D. A., Herndon, S., Shi, Q., Jimenez, J. L., Silva, P. J., Williams, P., Lanni, T., Drewnick, F., Demerjian, K. L., Kolb, C. E., and Worsnop, D. R.: Chase studies of particulate emissions from in-use New York City vehicles, Aerosol Sci. Tech., 38, 555-573, doi:10.1080/02786820490465504, 2004.

Canagaratna, M., Worsnop, D., Zhang, Q., and Jimenez, J. L.: Aerosol Mass Spectrometry of Organic Aerosol in Houston, Texas, International Aerosol Conference, St. Paul, MN, USA, 2006.

Canagaratna, M. R., Jayne, J. T., Jimenez, J. L., Allan, J. D., Alfarra, M. R., Zhang, Q., Onasch, T. B., Drewnick, F., Coe, H., Middlebrook, A., Delia, A., Williams, L. R., Trimborn, A. M., Northway, M. J., DeCarlo, P. F., Kolb, C. E., Davidovits, P., and Worsnop, D. R.: Chemical and microphysical characterization of ambient aerosols with the aerodyne aerosol mass spectrometer, Mass Spectrom. Rev., 26, 185-222, doi:10.1002/mas.20115, 2007.

Christensen, W., Williams, B., and Reese, C.: Bayesian Approaches for Pollution Source Location Identification and Apportionment, American Association of Aerosol Researchers Conference, Reno, NV, USA, 2007.

Crosier, J., Jimenez, J. L., Allan, J. D., Bower, K. N., Williams, P. I., Alfarra, M. R., Canagaratna, M. R., Jayne, J. T., Worsnop,
D. R., and Coe, H.: Technical note: Description and use of the new jump mass spectrum mode of operation for the aerodyne quadrupole aerosol mass spectrometers (Q-AMS), Aerosol Sci. Tech., 41, 865-872, doi:10.1080/02786820701501899, 2007.

DeCarlo, P. F., Kimmel, J. R., Trimborn, A., Northway, M. J., Jayne, J. T., Aiken, A. C., Gonin, M., Fuhrer, K., Horvath, T., Docherty, K. S., Worsnop, D. R., and Jimenez, J. L.: Field-deployable, high-resolution, time-of-flight aerosol mass spectrometer, Anal. Chem., 78, 8281-8289, doi:10.1021/ac061249n, 2006.

Drewnick, F., Hings, S. S., DeCarlo, P., Jayne, J. T., Gonin, M., Fuhrer, K., Weimer, S., Jimenez, J. L., Demerjian, K. L., Borrmann, S., and Worsnop, D. R.: A new time-of-flight aerosol mass spectrometer (TOF-AMS) - Instrument description and first field deployment, Aerosol Sci. Tech., 39, 637-658, doi:10.1080/02786820500182040, 2005.

Dzepina, K., Arey, J., Marr, L. C., Worsnop, D. R., Salcedo, D., Zhang, Q., Onasch, T. B., Molina, L. T., Molina, M. J., and Jimenez, J. L.: Detection of particle-phase polycyclic aromatic hydrocarbons in Mexico City using an aerosol mass spectrometer, Int. J. Mass spectrom., 263, 152-170, doi:10.1016/j.ijms.2007.01.010, 2007.

Engel-Cox, J. and Weber, S. A.: Compilation and Assessment of Recent Positive Matrix Factorization and UNMIX Receptor Model Studies on Fine Particulate Matter Source Apportionment for the Eastern United States, J. Air Waste Manage., 57, 13071316, doi:10.3155/1047-3289.57.11.1307, 2007.

Fuzzi, S., Decesari, S., Facchini, M. C., Matta, E., Mircea, M., and Tagliavini, E.: A simplified model of the water soluble organic component of atmospheric aerosols, Geophys. Res. Lett., 28, 4079-4082, 2001.

Hemann, J. G., Brinkman, G. L., Dutton, S. J., Hannigan, M. P., Milford, J. B., and Miller, S. L.: Assessing positive matrix factorization model fit: a new method to estimate uncertainty and bias in factor contributions at the measurement time scale, Atmos. Chem. Phys., 9, 497-513, 2009,

http://www.atmos-chem-phys.net/9/497/2009/.

Hoyer, P. O.: Non-negative matrix factorization with sparseness constraints, J. Mach. Learn. Res., 5, 1457-1469, 2004.

Huffman, J. A., Docherty, K. S., Aiken, A. C., Cubison, M. J., Ulbrich, I. M., DeCarlo, P. F., Sueper, D., Jayne, J. T., Worsnop, D. R., Ziemann, P. J., and Jimenez, J. L.: Chemically-resolved aerosol volatility measurements from two megacity field studies, Atmos. Chem. Phys. Discuss., 9, 2645-2697, 2009, http://www.atmos-chem-phys-discuss.net/9/2645/2009/.

Jayne, J. T., Leard, D. C., Zhang, X. F., Davidovits, P., Smith, K. A., Kolb, C. E., and Worsnop, D. R.: Development of an aerosol mass spectrometer for size and composition analysis of submicron particles, Aerosol Sci. Tech., 33, 49-70, 2000.

Jimenez, J. L., Jayne, J. T., Shi, Q., Kolb, C. E., Worsnop, D. R., Yourshaw, I., Seinfeld, J. H., Flagan, R. C., Zhang, X. F., Smith, K. A., Morris, J. W., and Davidovits, P.: Ambient aerosol sampling using the Aerodyne Aerosol Mass Spectrometer, J. Geophys. Res. Atmos., 108, 8425, doi:10.1029/2001JD001213, 2003.

Kanakidou, M., Seinfeld, J. H., Pandis, S. N., Barnes, I., Dentener, F. J., Facchini, M. C., Van Dingenen, R., Ervens, B., Nenes, A., Nielsen, C. J., Swietlicki, E., Putaud, J. P., Balkanski, Y., Fuzzi, S., Horth, J., Moortgat, G. K., Winterhalter, R., Myhre, C. E. L., Tsigaridis, K., Vignati, E., Stephanou, E. G., and Wilson, J.: 
Organic aerosol and global climate modelling: a review, Atmos. Chem. Phys., 5, 1053-1123, 2005,

http://www.atmos-chem-phys.net/5/1053/2005/.

Kim, E., Hopke, P. K., and Edgerton, E. S.: Source identification of Atlanta aerosol by positive matrix factorization, J. Air Waste Manage., 53, 731-739, 2003.

Lanz, V. A., Alfarra, M. R., Baltensperger, U., Buchmann, B., Hueglin, C., and Prévôt, A. S. H.: Source apportionment of submicron organic aerosols at an urban site by factor analytical modelling of aerosol mass spectra, Atmos. Chem. Phys., 7, 15031522, 2007,

http://www.atmos-chem-phys.net/7/1503/2007/.

Lanz, V. A., Alfarra, M. R., Baltensperger, U., Buchmann, B., Hueglin, C., Szidat, S., Wehrli, M. N., Wacker, L., Weimer, S., Caseiro, A., Puxbaum, H., and Prevot, A. S. H.: Source Attribution of Submicron Organic Aerosols during Wintertime Inversions by Advanced Factor Analysis of Aerosol Mass Spectra, Environ. Sci. Technol., 42, 214-220, doi:10.1021/es0707207, 2008.

Larsen, R. K. and Baker, J. E.: Source apportionment of polycyclic aromatic hydrocarbons in the urban atmosphere: A comparison of three methods, Environ. Sci. Technol., 37, 1873-1881, doi:10.1021/es0206184, 2003.

Lee, D. D. and Seung, H. S.: Learning the parts of objects by nonnegative matrix factorization, Nature, 401, 788-791, 1999.

Lee, E., Chan, C. K., and Paatero, P.: Application of positive matrix factorization in source apportionment of particulate pollutants in Hong Kong, Atmos. Environ., 33, 3201-3212, 1999.

Lingwall, J. W., Christensen, W. F., and Reese, C. S.: Dirichlet based Bayesian multivariate receptor modeling, Environmetrics, 19, 618-629, doi:10.1002/env.902, 2008.

Lu, J. H. and Wu, L. S.: Technical details and programming guide for a general two-way positive matrix factorization algorithm, J. Chemom., 18, 519-525, doi:10.1002/cem.894, 2004.

Marcolli, C., Canagaratna, M. R., Worsnop, D. R., Bahreini, R., de Gouw, J. A., Warneke, C., Goldan, P. D., Kuster, W. C., Williams, E. J., Lerner, B. M., Roberts, J. M., Meagher, J. F., Fehsenfeld, F. C., Marchewka, M., Bertman, S. B., and Middlebrook, A. M.: Cluster Analysis of the Organic Peaks in Bulk Mass Spectra Obtained During the 2002 New England Air Quality Study with an Aerodyne Aerosol Mass Spectrometer, Atmos. Chem. Phys., 6, 5649-5666, 2006, http://www.atmos-chem-phys.net/6/5649/2006/.

Maykut, N. N., Lewtas, J., Kim, E., and Larson, T. V.: Source apportionment of PM2.5 at an urban IMPROVE site in Seattle, Washington, Environ. Sci. Technol., 37, 5135-5142, doi:10.1021/es030370y, 2003.

Mohr, C., Huffman, J. A., Cubison, M. J., Aiken, A. C., Docherty, K. S., Kimmel, J. R., Ulbrich, I. M., Hannigan, M. P., and Jimenez, J. L.: Characterization of Primary Organic Aerosol Emissions from Meat Cooking, Trash Burning, and Motor Vehicles with High-Resolution Aerosol Mass Spectrometry and Comparison with Ambient and Chamber Observations, Environ. Sci. Technol., 43, 2443-2449, doi:10.1021/es8011518, 2009.

Murphy, D. M., Middlebrook, A. M., and Warshawsky, M.: Cluster analysis of data from the Particle Analysis by Laser Mass Spectrometry (PALMS) instrument, Aerosol Sci. Tech., 37, 382-391, doi:10.1080/02786820390125241, 2003.

Murphy, D. M.: The design of single particle laser mass spectrometers, Mass Spectrom. Rev., 26, 150-165, doi:10.1002/mas.20113, 2007.

Nemitz, E., Jimenez, J. L., Huffman, J. A., Ulbrich, I. M., Canagaratna, M. R., Worsnop, D. R., and Guenther, A. B.: An eddycovariance system for the measurement of surface/atmosphere exchange fluxes of submicron aerosol chemical species - First application above an urban area, Aerosol Sci. Tech., 42, 636657, doi:10.1080/02786820802227352, 2008.

Norris, G., Vedantham, R., Wade, K., Brown, S., Prouty, J., and Foley, C.: EPA Positive Matrix Factorization (PMF) 3.0 Fundamentals and User Guide, Washington DC, USA, 2008.

Paatero, P. and Tapper, U.: Analysis of different modes of factor analysis as least squares fit problems, Chemometr. Intell. Lab., 18, 183-194, 1993.

Paatero, P. and Tapper, U.: Positive Matrix Factorization: a nonnegative factor model with optimal utilization of error estimates of data values, Environmetrics, 5, 111-126, 1994.

Paatero, P.: Least squares formulation of robust non-negative factor analysis, Chemometr. Intell. Lab., 37, 23-35, 1997.

Paatero, P.: The multilinear engine - A table-driven, least squares program for solving multilinear problems, including the n-way parallel factor analysis model, J. Comput. Graph. Stat., 8, 854888, 1999.

Paatero, P., Hopke, P. K., Song, X. H., and Ramadan, Z.: Understanding and controlling rotations in factor analytic models, Chemometr. Intell. Lab., 60, 253-264, 2002.

Paatero, P. and Hopke, P. K.: Discarding or downweighting highnoise variables in factor analytic models, Anal. Chim. Acta, 490, 277-289, doi:10.1016/s0003-2670(02)01643-4, 2003.

Paatero, P., Hopke, P. K., Begum, B. A., and Biswas, S. K.: A graphical diagnostic method for assessing the rotation in factor analytical models of atmospheric pollution, Atmos. Environ., 39, 193-201, doi:10.1016/j.atmosenv.2004.08.018, 2005.

Paatero, P.: User's guide for positive matrix factorization programs PMF2.EXE and PMF3.EXE, University of Helsinki, Finland, 2007.

Paatero, P.: Interactive comment on "Interpretation of organic components from positive matrix factorization of aerosol mass spectrometric data" by I. M. Ulbrich et al., Atmos. Chem. Phys. Discuss., 8, S2059-S2068, 2008a.

Paatero, P.: Interactive comment on "Interpretation of organic components from positive matrix factorization of aerosol mass spectrometric data" by I. M. Ulbrich et al., Atmos. Chem. Phys. Discuss., 8, S2726-2732, 2008b.

Paatero, P. and Hopke, P. K.: Rotational tools for factor analytic models implemented by using the Multilinear Engine, in preparation, 2008.

Press, W. H., Teukolsky, S. A., Vetterling, W. T., and Flannery, B. P.: Modeling of Data, in: Numerical Recipes: The Art of Scientific Computing, 3rd ed., Cambridge University Press, New York, USA, 773-839, 2007a.

Press, W. H., Teukolsky, S. A., Vetterling, W. T., and Flannery, B. P.: Statistical Descritption of Data, in: Numerical Recipes: The Art of Scientific Computing, 3rd ed., Cambridge University Press, New York, USA, 720-772, 2007b.

Ramadan, Z., Song, X. H., and Hopke, P. K.: Identification of sources of Phoenix aerosol by positive matrix factorization, J. Air Waste Manage., 50, 1308-1320, 2000.

Reff, A., Eberly, S. I., and Bhave, P. V.: Receptor modeling of ambient particulate matter data using positive matrix factorization: 
Review of existing methods, J. Air Waste Manage., 57, 146-154, 2007.

Russell, L. M.: Aerosol organic-mass-to-organic-carbon ratio measurements, Environ. Sci. Technol., 37, 2982-2987, doi:10.1021/es026123w, 2003.

Sage, A. M., Weitkamp, E. A., Robinson, A. L., and Donahue, N. M.: Evolving mass spectra of the oxidized component of organic aerosol: results from aerosol mass spectrometer analyses of aged diesel emissions, Atmos. Chem. Phys., 8, 1139-1152, 2008, http://www.atmos-chem-phys.net/8/1139/2008/.

Schauer, J. J., Rogge, W. F., Hildemann, L. M., Mazurek, M. A., and Cass, G. R.: Source apportionment of airborne particulate matter using organic compounds as tracers, Atmos. Environ., 30, 3837-3855, 1996.

Schneider, J., Weimer, S., Drewnick, F., Borrmann, S., Helas, G., Gwaze, P., Schmid, O., Andreae, M. O., and Kirchner, U.: Mass spectrometric analysis and aerodynamic properties of various types of combustion-related aerosol particles, Int. J. Mass Spectrom., 258, 37-49, doi:10.1016/j.ijms.2006.07.008, 2006.

Stein, S., Mirokhin, Y., Tscekhovski, D., and Mallard, G.: The NIST Mass Spectral Search Program for the NIST/EPA/NIH Mass Spectral Library (Version 2.0), The Standard Reference Data Program of NIST, 2001.

Sullivan, A. P., Weber, R. J., Clements, A. L., Turner, J. R., Bae, M. S., and Schauer, J. J.: A method for on-line measurement of water-soluble organic carbon in ambient aerosol particles: Results from an urban site, Geophys. Res. Lett., 31, L13105, doi:10.1029/2004GL019681, 2004.

Szidat, S., Jenk, T. M., Synal, H. A., Kalberer, M., Wacker, L., Hajdas, I., Kasper-Giebl, A., and Baltensperger, U.: Contributions of fossil fuel, biomass-burning, and biogenic emissions to carbonaceous aerosols in Zurich as traced by C-14, J. Geophys. Res. Atmos., 111, D07206, doi:10.1029/2005JD006590, 2006.

Turpin, B. J. and Huntzicker, J. J.: Secondary Formation of Organic Aerosol in the Los-Angeles Basin - a Descriptive Analysis of Organic and Elemental Carbon Concentrations, Atmos. Environ. A Gen., 25, 207-215, 1991.

Turpin, B. J., Saxena, P., and Andrews, E.: Measuring and simulating particulate organics in the atmosphere: problems and prospects, Atmos. Environ., 34, 2983-3013, 2000.

Ulbrich, I. M., Lechner, M., and Jimenez, J. L.: AMS Spectral Database, online available at: http://cires.colorado.edu/ jimenez-group/AMSsd, 2007.

Ulbrich, I. M., Canagaratna, M. R., Zhang, Q., Worsnop, D. R., and Jimenez, J. L.: Interactive Comment on "Interpretation of organic components from positive matrix factorization of aerosol mass spectrometric data" by I. M. Ulbrich et al., Atmos. Chem. Phys. Discuss., 8, 6729-6791, 2008,

http://www.atmos-chem-phys-discuss.net/8/6729/2008/.
Williams, B. J., Goldstein, A. H., Kreisberg, N. M., and Hering, S. V.: An in-situ instrument for speciated organic composition of atmospheric aerosols: Thermal Desorption Aerosol GC/MS-FID (TAG), Aerosol Sci. Tech., 40, 627-638, doi:10.1080/02786820600754631, 2006.

Xie, Y. L., Hopke, P. K., Paatero, P., Barrie, L. A., and Li, S. M.: Identification of source nature and seasonal variations of arctic aerosol by positive matrix factorization, J. Atmos. Sci., 56, 249260, 1999.

Zhang, Q., Stanier, C. O., Canagaratna, M. R., Jayne, J. T., Worsnop, D. R., Pandis, S. N., and Jimenez, J. L.: Insights into the chemistry of new particle formation and growth events in Pittsburgh based on aerosol mass spectrometry, Environ. Sci. Technol., 38, 4797-4809, doi:10.1021/es035417u, 2004.

Zhang, Q., Alfarra, M. R., Worsnop, D. R., Allan, J. D., Coe, H., Canagaratna, M. R., and Jimenez, J. L.: Deconvolution and quantification of hydrocarbon-like and oxygenated organic aerosols based on aerosol mass spectrometry, Environ. Sci. Technol., 39, 4938-4952, doi:10.1021/es048568I, 2005a.

Zhang, Q., Canagaratna, M. R., Jayne, J. T., Worsnop, D. R., and Jimenez, J. L.: Time- and size-resolved chemical composition of submicron particles in Pittsburgh: Implications for aerosol sources and processes, J. Geophys. Res. Atmos., 110, D07S09, doi:10.1029/2004JD004649, 2005b.

Zhang, Q., Worsnop, D. R., Canagaratna, M. R., and Jimenez, J. L.: Hydrocarbon-like and oxygenated organic aerosols in Pittsburgh: insights into sources and processes of organic aerosols, Atmos. Chem. Phys., 5, 3289-3311, 2005c, http://www.atmos-chem-phys.net/5/3289/2005/.

Zhang, Q., Jimenez, J. L., Canagaratna, M. R., Allan, J. D., Coe, H., Ulbrich, I., Alfarra, M. R., Takami, A., Middlebrook, A. M., Sun, Y. L., Dzepina, K., Dunlea, E., Docherty, K., DeCarlo, P., Salcedo, D., Onasch, T. B., Jayne, J. T., Miyoshi, T., Shimono, A., Hatakeyama, N., Takegawa, N., Kondo, Y., Schneider, J., Drewnick, F., Weimer, S., Demerjian, K. L., Williams, P. I., Bower, K. N., Bahreini, R., Cottrell, L., Griffin, R. J., Rautianen, J., and Worsnop, D. R.: Ubiquity and Dominance of Oxygenated Species in Organic Aerosols in AnthropogenicallyInfluenced Northern Hemisphere Mid-latitudes, Geophys. Res. Lett., 34, L13801, doi:10.1029/2007GL029979, 2007 a.

Zhang, Q., Jimenez, J. L., Worsnop, D. R., and Canagaratna, M.: A case study of urban particle acidity and its influence on secondary organic aerosol, Environ. Sci. Technol., 41, 3213-3219, doi:10.1021/es061812j, 2007b. 